\title{
Pre-implantation exogenous progesterone and pregnancy in sheep. II. Effects on fetal- placental development and nutrient transporters in late pregnancy
}

Katherine M. Halloran ${ }^{1}$, Emily C. Hoskins ${ }^{1}$, Claire Stenhouse ${ }^{1}$, Robyn M. Moses ${ }^{1}$, Kathrin A. Dunlap', M. Carey Satterfield ${ }^{1}$, Heewon Seo ${ }^{2}$, Gregory A. Johnson², Guoyao Wu ${ }^{1}$ and Fuller W. Bazer ${ }^{*}$ (D)

\begin{abstract}
Background: Administration of progesterone (P4) to ewes during the first 9 to 12 days of pregnancy accelerates blastocyst development by day 12 of pregnancy, likely due to P4-induced up-regulation of key genes in uterine epithelia responsible for secretion and transport of components of histotroph into the uterine lumen. This study determined if acceleration of blastocyst development induced by exogenous P4 during the pre-implantation period affects fetal-placental development on day 125 of pregnancy. Suffolk ewes $(n=35)$ were mated to fertile rams and assigned randomly to receive daily intramuscular injections of either corn oil vehicle $(\mathrm{CO}, n=18)$ or $25 \mathrm{mg}$ progesterone in $\mathrm{CO}(\mathrm{P} 4, n=17)$ for the first 8 days of pregnancy. All ewes were hysterectomized on day 125 of pregnancy and: 1) fetal and placental weights and measurements were recorded; 2) endometrial and placental tissues were analyzed for the expression of candidate mRNAs involved in nutrient transport and arginine metabolism; and 3) maternal plasma, fetal plasma, allantoic fluid, and amniotic fluid were analyzed for amino acids, agmatine, polyamines, glucose, and fructose.
\end{abstract}

Results: Treatment of ewes with exogenous P4 did not alter fetal or placental growth, but increased amounts of aspartate and arginine in allantoic fluid and amniotic fluid, respectively. Ewes that received exogenous P4 had greater expression of mRNAs for SLC7A1, SLC7A2, SLC2A1, AGMAT, and ODC1 in endometria, as well as SLC1A4, SLC2A5, SLC2A8 and $O D C 1$ in placentomes. In addition, AZIN2 protein was immunolocalized to uterine luminal and glandular epithelia in P4-treated ewes, whereas AZIN2 localized only to uterine luminal epithelia in CO-treated ewes.

Conclusions: This study revealed that exogenous P4 administered in early pregnancy influenced expression of selected genes for nutrient transporters and the expression of a protein involved in polyamine synthesis on day 125 of pregnancy, suggesting a 'programming' effect of P4 on gene expression that affected the composition of nutrients in fetal-placental fluids.

Keywords: Amino acids, Endometrium, Fructose, Gene expression, Glucose, Placenta, Polyamines, Progesterone

* Correspondence: fbazer@cvm.tamu.edu

'Department of Animal Science, Texas A\&M University, College Station, TX

77843-2471, USA

Full list of author information is available at the end of the article

(c) The Author(s). 2021 Open Access This article is licensed under a Creative Commons Attribution 4.0 International License, which permits use, sharing, adaptation, distribution and reproduction in any medium or format, as long as you give appropriate credit to the original author(s) and the source, provide a link to the Creative Commons licence, and indicate if changes were made. The images or other third party material in this article are included in the article's Creative Commons licence, unless indicated otherwise in a credit line to the material. If material is not included in the article's Creative Commons licence and your intended use is not permitted by statutory regulation or exceeds the permitted use, you will need to obtain permission directly from the copyright holder. To view a copy of this licence, visit http://creativecommons.org/licenses/by/4.0/. The Creative Commons Public Domain Dedication waiver (http://creativecommons.org/publicdomain/zero/1.0/) applies to the data made available in this article, unless otherwise stated in a credit line to the data. 


\section{Background}

In sheep, the uterine luminal (LE), superficial glandular (sGE) and glandular (GE) epithelia are secretory cells that secrete and transport water, amino acids, hexose sugars, ions, growth factors, hormones, enzymes, cytokines, mitogens, and vitamins (collectively referred to as histotroph) into the uterine lumen early in pregnancy $[1,2]$. Histotroph is also transported into the fetal-placental vasculature and accumulates in allantoic and amniotic fluids to support growth and development of the conceptus (embryo/fetus and associated placental membranes) [1].

Amino acids are important building blocks for synthesis of peptides and protein-based molecules, including cell signaling molecules and hormones. Amino acids themselves are important for fetal-placental growth, or can act in concert with polyamines to mediate embryogenesis, placental growth, and angiogenesis to increase utero-placental blood flow [3-5]. Polyamines (putrescine, spermidine, and spermine) and agmatine are products of amino acid metabolism (primarily arginine, ornithine, and methionine) involved in mammalian embryogenesis, angiogenesis, and functional aspects of trophectoderm cells [4, 6-8]. By binding nucleic acids and proteins, polyamines affect gene transcription, mRNA translation, and protein synthesis, thereby participating in cell growth, proliferation, communication, membrane trafficking, and motility [9-13].

In most eukaryotic cells, glucose is the primary substrate for the production of adenosine triphosphate (ATP), nicotinamide adenine dinucleotide phosphate hydrogen (NADPH),ribose [14]. Glucose is an important metabolic substrate for the conceptus, but fetal and placental tissues generally do not produce it themselves and thus must rely on glucose from the mother [15-17]. Interestingly, fructose is the most abundant hexose sugar in the fetal fluids and blood of ungulates and cetaceans and is considered 'sequestered' from the mother [1820]. Fructose has multiple fates once inside a trophectoderm cell: it may enter the hexosamine biosynthesis pathway to produce glycosaminoglycans such as hyaluronic acid and UDP-N-acetylglucosamine, or its metabolic intermediates may be utilized to produce nucleic acids via one-carbon metabolism or NADPH and ribose sugars via the pentose phosphate pathway [21-23].

Molecules secreted as histotroph, the proteins that facilitate their transport, and the signaling mechanisms stimulated by these molecules are regulated in both a spatial (cell-specific) and temporal manner. In cattle, a delayed increase in circulating concentrations of progesterone (P4) reduces or delays secretion of interferon tau (IFNT), the pregnancy recognition signal in ruminants, and hinders conceptus development [24]. However, P4 supplementation after ovulation enhances bovine conceptus development and secretion of IFNT $[25,26]$. This indicates that P4 regulates early conceptus growth by modifying the timing of gene expression by cells of the uterine endometrium and their secretory activity. However, it is clearly the timing of early increases in concentrations of circulating $\mathrm{P} 4$ in maternal plasma, rather than the final concentrations of circulating P4, that induces accelerated development of the conceptus [27].

In previous studies, $\mathrm{P} 4$ was administered to ewes $36 \mathrm{~h}$ after mating to observe effects on development of preimplantation conceptuses [28-30]. In those studies, exogenous $\mathrm{P} 4$ administration advanced conceptus development by stimulating conceptus elongation earlier than conceptuses from control ewes. It was speculated that this was due to increased nutrient trafficking into the uterine lumen, as the results indicated increased expression of mRNAs for glucose and amino acid transporters in the uterine endometria of P4 treated ewes, as well as increases in recoverable nutrients, including glucose and arginine. Enhanced fetoplacental growth has been reported when ewes were administered P4 during the first 3 days of pregnancy [31, 32]. Those studies showed that conceptuses exposed to a P4-primed uterus had increased fetal crown-rump lengths and organ weights at day 76 of pregnancy, compared to fetuses from untreated ewes. However, little is known as to how these effects translate to the uterine environment and conceptus development in late gestation. The aim of this study was to determine if: 1) an exogenous systemic P4 treatment during the pre-implantation period of pregnancy has long-term effects on fetal and placental development, and 2) P4-induced modifications of uterine and placental gene expression influence the composition of uterine secretions, fetal fluids, and maternal and fetal plasma. Our hypothesis was that the P4-induced altered uterine environment that accelerates conceptus development during early pregnancy would result in advanced fetal-placental development due to alterations in expression of nutrient transporters and/or composition of fetal fluids in late gestation.

\section{Methods \\ Animals}

All experimental procedures followed the Guide for the Care and Use of Agriculture Animals in Research and Teaching and approved by the Institutional Animal Care and Use Committee of Texas A\&M University. The sheep used in this study were reproductively mature, as determined by exhibiting estrous cycles of normal duration in the presence of a vasectomized ram. All animals had an average body condition score (BCS) of 4 (ranged 3-5) for the duration of the study. Ewes were housed in a covered barn in group pens with free access to water 
and fed a commercially available complete pelleted sheep ration at a rate to meet NRC requirements [33].

\section{Experimental design and tissue collection}

Estrous cycles of mature Suffolk ewes (Ovis aries) were synchronized using a progesterone intravaginal insert (CIDR, Zoetis) for 12 days, and received an intramuscular injection of prostaglandin $F_{2 \alpha}$ (20 mg Lutalyse, Zoetis) upon CIDR removal. Ewes were observed for estrus (designated as day 0 ) in the presence of a vasectomized ram. Upon detection of estrus (day 0 ) ewes were placed with a fertile ram for $36 \mathrm{~h}$ and rams were changed every $12 \mathrm{~h}$ during this period. A total of five rams used in this study, and all ewes were exposed to three of these rams for the duration of estrus. Ewes were assigned randomly to receive daily intramuscular injections of either corn oil and ethanol vehicle (CO; $n=18)$ or $25 \mathrm{mg}$ progesterone dissolved in ethanol in corn oil vehicle (P4; $n=17)$ from day 1.5 (36 h after onset of estrus) through day 8 of pregnancy. On day 35 of gestation, ewes were subjected to transabdominal ultrasonography to determine pregnancy status. At day 125 of pregnancy, ewes were euthanized and hysterectomized after collecting blood in an EDTA coated tube via jugular venipuncture. Pregnancy type of each ewe was characterized by the number of fetuses (singleton vs twins) present at the time of hysterectomy. After the uteri were weighed, the chorioallantois was separated from the endometrium to expose the fetus and placental membranes. Samples of allantoic and amniotic fluids were collected, and volumes were determined. Allantoic and amniotic fluid were stored at $-20^{\circ} \mathrm{C}$ following centrifugation $(10,000 \times g$ for $10 \mathrm{~min})$. Sections of inter-caruncular endometrium and whole placentomes were collected and either frozen in liquid nitrogen and stored at $-80^{\circ} \mathrm{C}$ or fixed in $4 \%$ paraformaldehyde and dehydrated in $70 \%$ ethanol for $48 \mathrm{~h}$ prior to embedding in Paraffin wax. Fetal blood was collected by cardiac puncture and transferred to an EDTA coated tube. After separating the fetus and placenta, placental length and weight was measured, and the number of placentomes was determined. The fetuses were also weighed, and measurements indicative of fetal growth (crown-rump length, abdominal circumference, and chest circumference) were taken.

\section{Radioimmunoassay analysis of progesterone}

Maternal blood samples were collected immediately prior to euthanasia of ewes and stored on ice until processing. Plasma was collected following centrifugation $(8000 \times g$ for $7 \mathrm{~min})$ and stored at $-20^{\circ} \mathrm{C}$ until analyzed. Concentrations of progesterone in maternal plasma were determined as previously described [34] using a Progesterone Coated Tube Radioimmunoassay Kit (07-270102, MP Diagnostics) validated with P4 in ovine plasma.

\section{Analysis of amino acids, agmatine, and polyamines} Concentrations of amino acids, polyamines, and agmatine were determined in allantoic fluid, amniotic fluid, maternal plasma, and fetal plasma by high performance liquid chromatography (HPLC) using modified procedures described previously [35-37]. Briefly, $100 \mu \mathrm{L}$ of sample was acidified with $100 \mu \mathrm{L}$ of $1.5 \mathrm{~mol} / \mathrm{L} \mathrm{HClO}_{4}$ and neutralized with $50 \mu \mathrm{L} 2 \mathrm{~mol} / \mathrm{L} \mathrm{K}_{2} \mathrm{CO}_{3}$. The neutralized supernatant was diluted as needed and used for analysis by an HPLC method involving precolumn derivatization $o$-phthaldialdehyde (OPA) reagent I or II. OPA reagent I (for quantification of polyamines and agmatine) was prepared by dissolving $50 \mathrm{mg}$ of OPA (SigmaAldrich) and $50 \mathrm{mg} \mathrm{N}$-acetyl-cysteine (Sigma-Aldrich) in $1.25 \mathrm{~mL}$ of HPLC-grade methanol (Fisher Scientific) followed by $11.2 \mathrm{~mL} 0.04 \mathrm{~mol} / \mathrm{L}$ sodium borate ( $\mathrm{pH} 9.5)$, and $0.5 \mathrm{~mL}$ of Brij-23 (Sigma-Aldrich) OPA reagent II (for amino acids) was prepared by dissolving $50 \mathrm{mg}$ OPA in $1.25 \mathrm{~mL}$ HPLC-grade methanol, followed by $11.2 \mathrm{~mL}$ sodium borate ( $\mathrm{pH}$ 9.5), $50 \mu \mathrm{L}$ 2-mercaptoethanol, and $0.5 \mathrm{~mL}$ of Brij-23 (Sigma-Aldrich). The assay mixture contained $1.4 \mathrm{~mL}$ of HPLC-grade water (Fisher Scientific), $100 \mu \mathrm{L}$ of $1.2 \%$ benzoic acid (in $40 \mathrm{mmol} / \mathrm{L}$ sodium borate, $\mathrm{pH}$ 9.5), and $100 \mu \mathrm{L}$ of sample. The assay mixture was derivatized in an autosampler (model 712 WISP, Waters) with $30 \mathrm{mmol} / \mathrm{L}$ OPA reagent I or II, and $15 \mu \mathrm{L}$ of the derivatized mixture was injected into a Supelco 3- $\mu \mathrm{m}$ reversed-phase C18 column $(150 \mathrm{~mm} \times 4.6 \mathrm{~mm}$ inner diameter, Sigma-Aldrich). Amino acids, polyamines, and agmatine were separated using a solvent gradient comprised of solution A $(0.1 \mathrm{~mol} / \mathrm{L}$ sodium acetate, $18 \%$ methanol, and $1 \%$ tetrahydrofuran, $\mathrm{pH} 7.2$ ) and solution $\mathrm{B}$ (methanol). Amino acids, polyamines, and agmatine in the samples were quantified relative to authentic standards using Millenium-32 Software (Waters). Total amounts of amino acids, polyamines, and agmatine in allantoic and amniotic fluid were calculated by multiplying the concentration by the fluid volume.

\section{Quantification of glucose and fructose}

Allantoic and amniotic fluid, as well as fetal and maternal plasma, were analyzed for concentrations of glucose using a Glucose Assay Kit (STA-680, Cell Biolabs, Inc), as per the manufacturer's instructions. Each fluid type was assayed on one plate, and each plate was read on a spectrophotometric plate reader (Spectramax M2, Molecular Devices) $(\mathrm{nm}=540 \mathrm{~nm})$ within $5 \mathrm{~min}$ after incubation. Kit standards were used to generate a standard curve from 0 to $100 \mu \mathrm{mol} / \mathrm{L}$, and maternal plasma, fetal plasma, allantoic fluid, and amniotic fluid, were diluted (1:100, $1: 80,1: 5$, and $1: 2$, respectively) with $1 \times$ assay buffer to ensure sample concentrations were within the limits of the standard curve The limit of detection of the assay was $6.25 \mu \mathrm{mol} / \mathrm{L}$. The intra and inter assay 
coefficients of variation were $2.5 \%$ and $11.5 \%$, respectively. Allantoic and amniotic fluid data are expressed as total glucose [volume of fluid $(\mathrm{mL}) \times$ concentration of glucose $(\mu \mathrm{mol} / \mathrm{L})]$ in the respective fluids.

Maternal plasma, fetal plasma, allantoic fluid, and amniotic fluid were analyzed for concentrations of fructose using a Fructose Assay Kit (EFRU-100; BioAssay Systems), as per manufacturer's instructions. Each fluid type was assayed on one plate, and each plate was read immediately on a spectrophotometric plate reader $(\mathrm{nm}=$ 565). Kit standards were used to generate a standard curve from 0 to $1000 \mu \mathrm{mol} / \mathrm{L}$, and allantoic fluid, amniotic fluid, and fetal plasma were diluted (1:8, 1:15, and 1: 10 , respectively) with double distilled water to ensure sample concentrations were within the limits of the standard curve. The limit of detection of the assay was $12 \mu \mathrm{mol} / \mathrm{L}$. The intra and inter assay coefficients of variation were $5.4 \%$ and $9.5 \%$, respectively. Allantoic and amniotic fluid data are expressed as total fructose [volume of fluid $(\mathrm{mL}) \times$ concentration of fructose $\mu \mathrm{mol} / \mathrm{L}$ ] in the respective fluids.

\section{RNA extraction, CDNA synthesis, and quantitative real- time PCR analysis}

RNA was extracted from ovine endometria and placentomes using Trizol (Invitrogen) as per manufacturer's instructions and treated with RNase-Free DNase (Qiagen). The RNA was further purified using the RNeasy Mini Kit (Qiagen) as per manufacturer's instructions. The RNA was quantified using a NanoDrop (ND-1000 Spectrophotometer), and the quality was assessed by electrophoresis (2100 Bioanalyzer, Agilent Technologies). Only samples with an RNA integrity number (RIN) greater than 7 were used. First-strand cDNAs were synthesized from $5 \mu \mathrm{g}$ of total RNA using oligo (deoxythymidine) primers and SuperScript II Reverse Transcriptase (Invitrogen) as per the manufacturer's instructions. Negative controls without reverse transcriptase were included to verify a lack of genomic contamination.

Quantitative polymerase chain reaction (qPCR) was performed using the ABI prism $7900 \mathrm{HT}$ system (Applied Biosystems, Foster City, CA, United States) with Power SYBR Green PCR Master Mix (Applied Biosystems) as specified by the manufacturer to determine the levels of expression of mRNAs encoding for genes of interest. Primer sequences are listed in Supplementary Table 1. Primer efficiency and specificity were tested by generating a standard curve from pooled cDNA and by the inclusion of a dissociation curve for the $\mathrm{qPCR}$ reaction, respectively. Serial dilutions of pooled cDNA in nuclease-free water ranging from 1:2 to 1:256 were used as standards. All primer sets used amplified a single product (i.e. a dissociation curve with a single peak) and had an efficiency of between 95\% and 105\%. Each well contained 10\% diluted cDNA, 30\% nuclease-free water, $10 \%$ primer, and $50 \%$ SYBR Green reaction mix in a $10-$ $\mu \mathrm{L}$ reaction volume. Each sample was run in triplicate using the following conditions: $50^{\circ} \mathrm{C}$ for $2 \mathrm{~min}, 95^{\circ} \mathrm{C}$ for $10 \mathrm{~min}$, followed by 40 cycles of $95^{\circ} \mathrm{C}$ for $15 \mathrm{~s}$ and $60^{\circ} \mathrm{C}$ for $1 \mathrm{~min}$. All reactions were performed at an annealing temperature of $60^{\circ} \mathrm{C}$. For primers of interest with lower expression (i.e. Cq values above 30; AZIN2 and AGMA T), $1 \mu \mathrm{L}$ of cDNA was used in a modified preamplification step [38] using a Thermocycler (Eppendorf AG). Briefly, cDNA, nuclease-free water, forward and reverse primer, and SYBR were combined as described above in a $20-\mu \mathrm{L}$ volume. The reaction was performed with the following conditions for 15 cycles: $94^{\circ} \mathrm{C}$ for $30 \mathrm{~s}$, $58^{\circ} \mathrm{C}$ for $30 \mathrm{~s}$, and $72^{\circ} \mathrm{C}$ for $30 \mathrm{~s}$. The reference genes $S D H A$ and GAPDH were determined to have stable expression in endometria and placentomes, respectively, by testing for effects of treatment, pregnancy type, fetal sex, and their combinations. $P$ values $>0.1$ indicated that expression of these genes was unaffected, and thus were used to normalize expression of mRNAs of interest. The abundance of mRNAs was quantified using the $\Delta \Delta \mathrm{Cq}$ method, and these values are represented in Figs. 1 and 2 [28].

\section{Localization of proteins}

Immunohistochemical localization of SLC2A5, ODC1, and AZIN2 proteins in endometria, and AZIN2 and AGMAT proteins in placentomes, was performed using a Vectastain $\mathrm{ABC}$ Universal Kit (Vector Laboratories, PK-6200) as per manufacturer's instructions. Antibody information is listed in Supplementary Table 2. Briefly, sections of endometria and placentomes were cut $(5 \mu \mathrm{m})$ and rehydrated through CitriSolv (Decon Labs, Inc.) and decreasing concentrations of ethanol to water. For SLC2A5, ODC1, and AGMAT proteins, antigen retrieval was performed using boiling $0.1 \mathrm{~mol} / \mathrm{L}$ sodium citrate buffer (pH 6). For AZIN2, slides were incubated for 8 min at $37^{\circ} \mathrm{C}$ in a solution of $0.5 \mathrm{mg} / \mathrm{mL}$ Protease (Sigma-Aldrich, P5147) dissolved in 1× PBS (phosphate buffered saline) for antigen retrieval. Endogenous peroxide activity was blocked by incubating slides in $0.3 \%$ hydrogen peroxide (Sigma Aldrich) in methanol at room temperature for $15 \mathrm{~min}$. Sections were incubated for $1 \mathrm{~h}$ at room temperature in normal horse serum (Vectastain ABC Universal Kit) to block non-specific binding sites. Sections were incubated in primary antibody in a humidified chamber for SLC2A5 (Sigma-Aldrich, AV42096; 1:100 dilution), ODC1 (Abcam, ab97395; 1: 450 dilution), and AZIN2 (Abcam, ab192771; 1:350 dilution) in endometria, and AZIN2 (1:250 dilution) and AGMAT (Abcam, ab231894; 1:100 dilution) in placentomes. Rabbit immunoglobulin G (IgG) (Vector Laboratories) was used as a negative control at the same concentrations for each antibody used. After overnight 

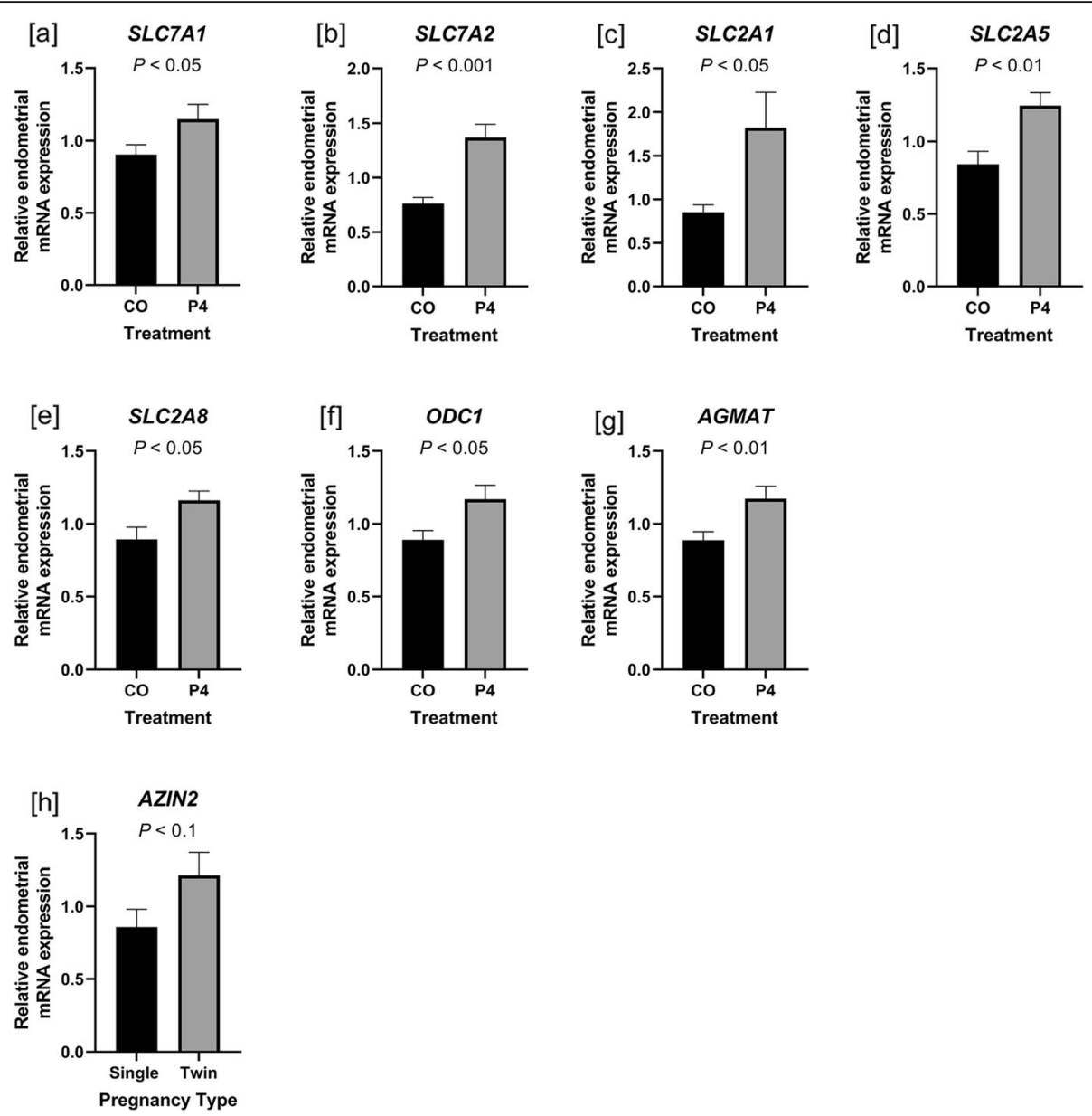

Fig. 1 Endometrial expression of mRNAs affected by treatment (a-g) and fetal number (h) in ewes treated with either progesterone (P4) or corn oil (CO). Expression of mRNAs for SLC7A1 (a), SLC7A2 (b), SLC2A1 (c), SLC2A5 (d), SLC2A8 (e), ODC1 (f), and AGMAT (g) was greater in endometria of ewes treated with P4 compared to ewes treated with CO. Expression of mRNAs for AZIN2 (h) was greater in endometria of ewes pregnant with two fetuses compared to those with one fetus. Mean values and SEM are presented. $n=5-9$ samples per group

incubation at $4{ }^{\circ} \mathrm{C}$, slides were washed in PBS and incubated in a humidified chamber with biotinylated antirabbit IgG secondary antibody (Vectastain Elite ABC Kit; 1:200 dilution in PBS with $1.5 \%$ normal horse serum) at $37^{\circ} \mathrm{C}$ for $1 \mathrm{~h}$. Slides were then incubated at $37^{\circ} \mathrm{C}$ for 30 min in a humidified chamber with Vectastain Elite $A B C$ Reagent (Vectastain Elite ABC Kit). Immunoreactive protein was visualized using 3,3'-diaminobenzidine tetrahydrochloride (Sigma-Aldrich). Sections were counterstained with hematoxylin and dehydrated through increasing concentrations of ethanol to CitriSolv before affixing coverslips with Permount mounting medium (Fisher Scientific). Images were captured of representative fields using a Nikon Eclipse Ni microscope and NIS Software (Nikon).

\section{Image analysis}

AZIN2-stained endometrial stromal images taken at $10 \times$ magnification containing uterine glands were analyzed using ImageJ. Regions of the stroma containing uterine glands were analyzed in the same image. Images were split into red, green, and blue channels. Using the free-hand drawing tool, the percentage staining per uterine gland was quantified using the blue channel at a threshold of 100-pixel intensity.

\section{Statistical analysis}

Statistical analyses were performed using either SAS (Version 9.4) or Genstat. Normality of the distribution of data was assessed, and a $P$ value of $\geq 0.05$ indicated that the data were not normally distributed. The ROUT test for outliers was performed to identify data points for exclusion. Normality was reassessed after exclusion of the outliers. Transformations were carried out if necessary to achieve a Gaussian distribution. ANOVA with a post-hoc Tukey test was performed on data with a normal distribution. If data were not normally 


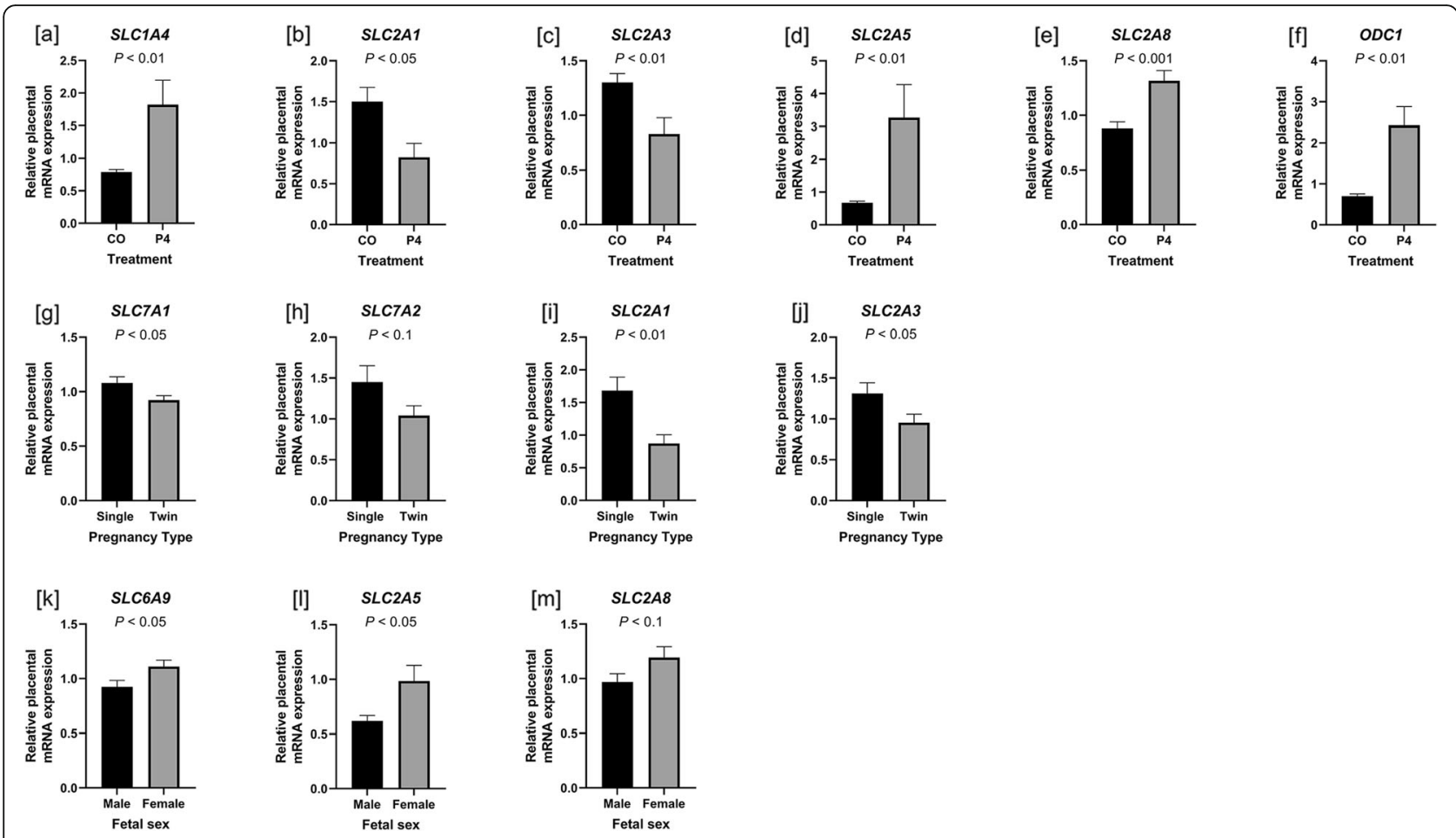

Fig. 2 Placental expression of mRNAs affected by treatment (a-f), fetal number $(\mathbf{g}-\mathbf{j})$, and fetal sex $(\mathbf{k}-\mathbf{m})$ in ewes treated with either progesterone (P4) or corn oil (CO). Expression of mRNAs for SLC1A4 (a), SLC2A5 (d), SLC2A8 (e), and ODC1 (f) was greater in placentomes of ewes treated with P4 compared to those treated with CO, while SLC2A1 (b) and SLC2A3 (c) mRNA expression was lower in P4-treated ewes. Expression of mRNAs for SLC7A1 (g), SLC7A2 (h), SLC2A1 (i), and SLC2A3 (j) was greater in placentomes of pregnancies with one fetus than those with two fetuses. Expression of mRNAs for SLC6A9 ( $\mathbf{k})$, SLC2A5 (I), and SLC2A8 $(\mathbf{m})$ was greater in placentomes of placentae associated with female compared to male fetuses. Mean values and SEM are presented. $n=5-9$ samples per group

distributed, Kruskal-Wallis and Mann Whitney tests were performed.

\section{Results}

A summary of measurements affected by progesterone (P4) treatment, pregnancy type, and fetal sex may be found in Supplementary Table 3.

\section{Comparison of pregnancy rates, pregnancy type, and fetal sex}

To determine whether P4 treatment influenced pregnancy rates, the number of pregnancies were compared between the P4- and $\mathrm{CO}$ - treated groups at day 35 of gestation. P4-treated ewes had a significantly lower pregnancy rate $(64.7 \%)$ compared to CO-treated ewes (94.4\%) $(P<0.05)$. At necropsy, there was no significant difference in pregnancy rate between $\mathrm{CO}-(n=14)$ and P4- $(n=10)$ treated ewes $(P>0.05)$. There were 10 total ewes pregnant with two fetuses (5 CO- and 5 P4-treated ewes), and 14 were pregnant with singletons ( $9 \mathrm{CO}$ - and 5 P4-treated ewes) at necropsy. There were a total of 21 male fetuses and 13 female fetuses $(12$ males and $7 \mathrm{fe}$ males from CO-treated ewes, and 9 males and 6 females from P4-treated ewes). There were no differences in pregnancy type (singleton vs. twins) or distribution of fetal sex due to treatment $(P>0.05)$.

\section{Concentrations of progesterone in maternal plasma}

There was no difference $(P>0.05)$ in concentrations of progesterone in maternal plasma between P4-treated $(22.4 \pm 2.4 \mathrm{ng} / \mathrm{mL})$ and CO-treated $(21.5 \pm 1.6 \mathrm{ng} / \mathrm{mL})$ ewes on day 125 of pregnancy. An increase in systemic P4 for ewes treated with P4 was confirmed on day 9 of pregnancy (Hoskins et al., unpublished results).

\section{Fetal and placental phenotypes}

Measurements of fetal development, including weight, crown-rump length, abdominal circumference, and chest circumference are summarized in Table 1. Fetal weight, crown-rump length, abdominal circumference, chest circumference, as well as placental weight, placental length, and number of placentomes were not different between treatment groups $(P>0.05)$. Male fetuses were heavier $(P<0.05)$ and had greater chest circumferences $(P<$ $0.05)$ than female fetuses. Placental weight, placental length, number of placentomes, and volumes of allantoic and amniotic fluid were also measured as indicators of placental development (Table 1). Placental length $(P<$ 
Table 1 Parameters of growth for fetuses and placentae

\begin{tabular}{|c|c|c|c|c|c|c|}
\hline \multirow[b]{3}{*}{ Measurement } & \multicolumn{6}{|l|}{ Effect } \\
\hline & \multicolumn{2}{|l|}{ Treatment } & \multicolumn{2}{|l|}{ Pregnancy type } & \multicolumn{2}{|l|}{ Fetal sex } \\
\hline & $\mathrm{CO}$ & P4 & Single & Twin & Male & Female \\
\hline Fetal weight, g & $3648 \pm 174.1$ & $3776 \pm 157.1$ & $4089 \pm 181.7^{a}$ & $3435 \pm 127.2^{b}$ & $3916 \pm 137^{\mathrm{a}}$ & $3470 \pm 98.7^{b}$ \\
\hline Fetal CRL, cm & $53.1 \pm 0.8$ & $52.9 \pm 1$ & $54 \pm 1$ & $52.3 \pm 0.6$ & $53.4 \pm 0.8$ & $52.3 \pm 0.9$ \\
\hline Fetal ab. circ., cm & $33.7 \pm 0.7$ & $33.1 \pm 0.8$ & $34.3 \pm 0.8$ & $32.9 \pm 0.7$ & $33.91 \pm 0.6$ & $32.6 \pm 0.9$ \\
\hline Fetal chest circ., cm & $32.6 \pm 0.6$ & $33.1 \pm 0.5$ & $33.9 \pm 0.5^{\mathrm{a}}$ & $32.1 \pm 0.5^{b}$ & $33.4 \pm 0.4^{\mathrm{a}}$ & $31.7 \pm 0.7^{b}$ \\
\hline Placenta weight, g & $602.3 \pm 35.4$ & $522.7 \pm 44.7$ & $630.7 \pm 41.2$ & $522.8 \pm 36.2$ & $503.7 \pm 43.4$ & $601.9 \pm 35.4$ \\
\hline Placental length, cm & $100.6 \pm 4.7$ & $99.4 \pm 6.7$ & $116.7 \pm 4.9^{\mathrm{a}}$ & $87.3 \pm 3.4^{b}$ & $92.4 \pm 4.7$ & $103.7 \pm 5$ \\
\hline Number of cotyledons & $54 \pm 3.7$ & $50.6 \pm 5.2$ & $67 \pm 3.6^{a}$ & $42.5 \pm 2.7^{b}$ & $47.2 \pm 4.3$ & $55.6 \pm 3.9$ \\
\hline Allantoic fluid volume, $\mathrm{mL}$ & $617.2 \pm 56.1$ & $651.9 \pm 58.7$ & $662.1 \pm 68.3$ & $609.7 \pm 49.6$ & $564.7 \pm 81.7$ & $665.6 \pm 44.2$ \\
\hline Amniotic fluid volume, $\mathrm{mL}$ & $598.8 \pm 47.6$ & $665.9 \pm 87.1$ & $660.4 \pm 55.8$ & $602.6 \pm 66.5$ & $688.8 \pm 87.5$ & $592.4 \pm 50.8$ \\
\hline
\end{tabular}

Measurements of fetuses and placentae from ewes treated with either CO $(n=14)$ or P4 $(n=10)$, singleton pregnancies $(n=14)$ or twin pregnancies $(n=10)$, and male fetuses $(n=21)$ or female fetuses $(n=13)$. Values represent means \pm SEM. Different superscripts within Effect columns are significantly different $(P<0.05)$

$0.01)$ and number of placentomes per placenta $(P<0.01)$ were greater in pregnancies with a singleton fetus than twin-fetuses. Volumes of allantoic fluid and amniotic fluid were not different due to P4 treatment, fetal number, or their interaction $(P>0.05)$.

\section{Amino acids in maternal and fetal plasma, allantoic fluid, and amniotic fluid}

Concentrations of amino acids in maternal and fetal plasma are summarized in Tables 2 and 3, respectively, and Supplementary Fig. 1. The most abundant amino acids in maternal plasma were glutamate, glycine, and alanine. There were no differences in concentrations of amino acids in maternal plasma between P4- and COtreated ewes $(P>0.05)$. Concentrations of aspartate, threonine, arginine, valine, and ornithine were greater $(P<0.05)$ in plasma of ewes with a singleton fetus compared to those for ewes with twin fetuses. Similarly, there was a tendency for greater concentrations of citrulline in plasma of ewes with a single fetus $(P<0.1)$. Interestingly, concentrations of glutamate in maternal plasma were less $(P<0.05)$ for ewes with a singleton fetus compared to twin fetuses. Arginine was more abundant in maternal plasma of P4-treated ewes carrying twins compared to P4-treated ewes carrying a singleton $(P<0.05)$.

Overall, glutamate, serine, glycine, and alanine were most abundant in fetal plasma. There were no differences in concentrations of amino acids in fetal plasma from P4- or COtreated ewes $(P>0.05)$. Concentrations of aspartate $(P<$ $0.05)$, serine $(P<0.05)$, and glycine $(P<0.1)$ were greater for fetuses from twin compared to singleton fetus pregnancies. Conversely, concentrations of threonine $(P<0.05)$, $\beta$ alanine $(P<0.1)$, tryptophan $(P<0.1)$, methionine $(P<$ $0.05)$, and valine $(P<0.1)$ were lower in plasma of fetuses from twin pregnancies than fetuses from singleton pregnancies. Threonine was the only amino acid in greater concentrations in plasma of male fetuses $(P<0.05)$. A comparison of maternal and fetal plasma indicated greater concentrations of all amino acids, except for arginine and citrulline, in fetal plasma than maternal plasma $(P<0.001)$.

Total amounts of amino acids in allantoic and amniotic fluids, calculated by multiplying the concentration by the volume of the respective placental fluid, are summarized in Tables 4 and 5, respectively, and Supplementary Fig. 1. There was less glutamate in allantoic fluid of P4-treated than CO-treated ewes $(P<0.05)$, while allantoic fluid of P4treated ewes tended to have greater amounts of aspartate $(P<0.1)$ than that for CO-treated ewes. Allantoic fluid from singleton pregnancies had more taurine than allantoic fluid from twin pregnancies $(P<0.05)$. There was more serine, glutamine, histidine, glycine, threonine, arginine, taurine, tryptophan, phenylalanine, and isoleucine in allantoic fluid associated with male than female fetuses $(P<0.05)$, and total amounts of leucine also tended to be greater in allantoic fluid associated with male fetuses $(P<0.1)$. Allantoic fluid associated with male fetuses of P4treated ewes had significantly $(P<0.05)$ greater abundances of arginine, histidine, glutamine, glycine, and threonine, with a tendency $(P<0.1)$ for greater amounts of aspartate, tryptophan, taurine, and leucine compared to allantoic fluid associated with female fetuses of P4-treated ewes.

Total amounts of arginine were greater in amniotic fluid of $P 4$-treated than CO-treated ewes $(P<0.05)$. Lysine $(P<0.05)$ and tryptophan $(P<0.1)$ were greater in amniotic fluid of singleton pregnancies compared to amniotic fluid of twin pregnancies. Ornithine tended to be present in greater amounts in amniotic fluid associated with female compared to male fetuses $(P<0.1)$. 
Table 2 Concentrations of amino acids, agmatine, polyamines $(\mathrm{nmol} / \mathrm{mL})$, and hexose sugars $(\mu \mathrm{mol} / \mathrm{L})$ in maternal plasma

\begin{tabular}{|c|c|c|c|c|}
\hline \multirow[b]{3}{*}{ Nutrient } & \multicolumn{4}{|l|}{ Effect } \\
\hline & \multicolumn{2}{|l|}{ Treatment } & \multicolumn{2}{|l|}{ Pregnancy type } \\
\hline & $\mathrm{CO}$ & P4 & Single & Twin \\
\hline \multicolumn{5}{|l|}{ Amino acid } \\
\hline Alanine & $176.9 \pm 16$ & $173.4 \pm 11.1$ & $172.1 \pm 11.1$ & $179.8 \pm 19.5$ \\
\hline$\beta$-Alanine & $10.9 \pm 1.3$ & $10.2 \pm 0.6$ & $10.7 \pm 1.2$ & $10.4 \pm 1$ \\
\hline Arginine & $118 \pm 8.4$ & $121.7 \pm 11.3$ & $134.7 \pm 8.2^{\mathrm{a}}$ & $100.6 \pm 7.9^{b}$ \\
\hline Asparagine & $24 \pm 2.5$ & $22.6 \pm 1.8$ & $21.5 \pm 2.2$ & $25.8 \pm 2.3$ \\
\hline Aspartate & $1.0 \pm 0.2$ & $0.84 \pm 0.2$ & $1.2 \pm 0.2^{\mathrm{a}}$ & $0.67 \pm 0.2^{b}$ \\
\hline Citrulline & $96 \pm 14.1$ & $102.7 \pm 10.3$ & $112.6 \pm 15.1$ & $81 \pm 6.1$ \\
\hline Glutamate & $202.1 \pm 14.7$ & $213.6 \pm 26.1$ & $181.1 \pm 12.1^{\mathrm{a}}$ & $239.3 \pm 23.4^{b}$ \\
\hline Glutamine & $56.6 \pm 6.9$ & $50.5 \pm 11.1$ & $50.3 \pm 8.3$ & $59.1 \pm 8.7$ \\
\hline Glycine & $428.2 \pm 28.2$ & $440.4 \pm 25$ & $431.4 \pm 25$ & $435.2 \pm 28.8$ \\
\hline Histidine & $23.5 \pm 1.8$ & $22.2 \pm 1.8$ & $22.4 \pm 1.5$ & $23.7 \pm 1.9$ \\
\hline Isoleucine & $74.1 \pm 7.3$ & $66.3 \pm 5.4$ & $75.6 \pm 6.3$ & $65.1 \pm 7.6$ \\
\hline Leucine & $114.9 \pm 10.8$ & $94.5 \pm 5.6$ & $115.1 \pm 8.4$ & $96.2 \pm 11.6$ \\
\hline Lysine & $71.2 \pm 9$ & $68.2 \pm 9.8$ & $75.1 \pm 9.3$ & $63.5 \pm 9$ \\
\hline Methionine & $20 \pm 1.8$ & $20.7 \pm 1.3$ & $20.7 \pm 1.4$ & $19.8 \pm 2.1$ \\
\hline Ornithine & $23.6 \pm 3.7$ & $23.7 \pm 3.6$ & $28.6 \pm 3.7^{\mathrm{a}}$ & $17.2 \pm 2.7^{b}$ \\
\hline Phenylalanine & $36.7 \pm 3.2$ & $34.8 \pm 1.5$ & $37.1 \pm 1.9$ & $37.2 \pm 3.9$ \\
\hline Serine & $66.7 \pm 7.8$ & $58.3 \pm 4.8$ & $57.6 \pm 7.1$ & $70.6 \pm 6.7$ \\
\hline Taurine & $60.3 \pm 5.3$ & $61.6 \pm 5.9$ & $61.4 \pm 5.1$ & $60.2 \pm 6.2$ \\
\hline Threonine & $68.1 \pm 9$ & $54.6 \pm 5.2$ & $75.1 \pm 7.2^{\mathrm{a}}$ & $46.9 \pm 7.5^{b}$ \\
\hline Tryptophan & $22.4 \pm 1.9$ & $22 \pm 1.7$ & $23.2 \pm 1.4$ & $21.1 \pm 2.4$ \\
\hline Tyrosine & $49.3 \pm 4.3$ & $49 \pm 3.6$ & $53.1 \pm 3.4$ & $44.2 \pm 4.8$ \\
\hline Valine & $138.9 \pm 14.3$ & $119.1 \pm 10.7$ & $148.2 \pm 10.3^{\mathrm{a}}$ & $109.1 \pm 15.5^{b}$ \\
\hline \multicolumn{5}{|c|}{ Agmatine and polyamines } \\
\hline Agmatine & $130.3 \pm 13.4$ & $166.1 \pm 18.3$ & $155.6 \pm 15.4$ & $130.5 \pm 6.1$ \\
\hline Putrescine & $2.1 \pm 0.6$ & $2.3 \pm 0.8$ & $2.9 \pm 0.8$ & $1.3 \pm 0.3$ \\
\hline Spermidine & $1.7 \pm 0.3$ & $1.7 \pm 0.4$ & $2.1 \pm 0.3$ & $1.2 \pm 0.4$ \\
\hline Spermine & $0.73 \pm 0.2$ & $0.45 \pm 0.1$ & $0.76 \pm 0.2$ & $0.44 \pm 0.1$ \\
\hline \multicolumn{5}{|l|}{ Hexose sugars } \\
\hline Glucose & $1485 \pm 162.9$ & $1617 \pm 110.7$ & $1691 \pm 137.9$ & $1296 \pm 144.2$ \\
\hline Fructose & $331.5 \pm 33.8$ & $303.2 \pm 39.8$ & $324.3 \pm 32.9$ & $313.2 \pm 41.7$ \\
\hline
\end{tabular}

Concentrations of nutrients in maternal plasma from ewes treated with either CO $(n=14)$ or P4 $(n=10)$ that carried either singleton $(n=14)$ or twin pregnancies $(n=10)$. Values represent means \pm SEM. Different superscripts within Effect columns are significantly different $(P<0.05)$

Agmatine and polyamines in maternal plasma, fetal plasma, allantoic fluid, and amniotic fluid

Concentrations of agmatine and polyamines in maternal and fetal plasma are summarized in Tables 2 and 3, respectively, and Supplementary Fig. 2. Overall, concentrations of agmatine in both fetal and maternal plasma were greater $(P<0.001)$ than spermidine, spermine, and putrescine. A comparison of fetal and maternal plasma revealed greater concentrations of agmatine, spermine, and putrescine in fetal plasma compared to maternal plasma $(P<0.001)$.
There were no differences in concentrations of agmatine or polyamines in maternal plasma due to $\mathrm{P} 4$ treatment $(P>0.05)$. Spermidine tended to be in greater abundance in plasma of ewes with a singleton fetus compared to ewes with twin fetuses $(P<0.1)$.

Putrescine tended to be more abundant in fetal plasma of CO-treated ewes with a twin pregnancy than P4-treated ewes with a twin pregnancy $(P<0.1)$, and greater concentrations of putrescine were detected in plasma of fetuses from singleton than twin 
Table 3 Concentrations of amino acids, agmatine, polyamines $(\mathrm{nmol} / \mathrm{mL})$, and hexose sugars $(\mu \mathrm{mol} / \mathrm{L})$ in fetal plasma

\begin{tabular}{|c|c|c|c|c|c|c|}
\hline \multirow[b]{3}{*}{ Nutrient } & \multicolumn{6}{|l|}{ Effect } \\
\hline & \multicolumn{2}{|l|}{ Treatment } & \multicolumn{2}{|c|}{ Pregnancy type } & \multicolumn{2}{|l|}{ Fetal sex } \\
\hline & $\mathrm{CO}$ & P4 & Single & Twin & Male & Female \\
\hline \multicolumn{7}{|l|}{ Amino acid } \\
\hline Alanine & $512.8 \pm 36.7$ & $492.3 \pm 55.6$ & $456 \pm 38.6^{a}$ & $545.8 \pm 46.6^{b}$ & $500.5 \pm 40.5$ & $509 \pm 51.6$ \\
\hline$\beta$-Alanine & $129.6 \pm 12.6$ & $121 \pm 15.5$ & $144.5 \pm 16.5$ & $109.5 \pm 9.8$ & $126.8 \pm 9.8$ & $124.5 \pm 19.9$ \\
\hline Arginine & $137.2 \pm 14.7$ & $138.4 \pm 10.6$ & $135.6 \pm 11.1$ & $139.6 \pm 14.9$ & $144.6 \pm 13.1$ & $127 \pm 12.6$ \\
\hline Asparagine & $59.4 \pm 6.2$ & $54.3 \pm 4.8$ & $54 \pm 4.7$ & $60 \pm 6.5$ & $60 \pm 6.2$ & $53 \pm 4$ \\
\hline Aspartate & $33.1 \pm 4.1$ & $32.6 \pm 5.4$ & $25.4 \pm 3^{a}$ & $39.4 \pm 5^{b}$ & $31.6 \pm 4.4$ & $34.7 \pm 5$ \\
\hline Citrulline & $87.3 \pm 6.1$ & $93.7 \pm 11.7$ & $98.9 \pm 9.2$ & $82.3 \pm 7.8$ & $87.3 \pm 5.9$ & $94.1 \pm 12.6$ \\
\hline Glutamate & $600.5 \pm 58.5$ & $549.9 \pm 78.2$ & $507.4 \pm 62.9$ & $640.9 \pm 66.2$ & $578.5 \pm 62.4$ & $578.8 \pm 73.5$ \\
\hline Glutamine & $232.7 \pm 19.1$ & $245.9 \pm 25.1$ & $218.5 \pm 20.5$ & $255.8 \pm 21.5$ & $242.6 \pm 19.1$ & $232.2 \pm 25.5$ \\
\hline Glycine & $556.6 \pm 56.7$ & $622.6 \pm 68.4$ & $495.5 \pm 36.3^{\mathrm{a}}$ & $663.6 \pm 70.3^{b}$ & $566.2 \pm 55.1$ & $613.6 \pm 72.3$ \\
\hline Histidine & $49.7 \pm 3$ & $55.4 \pm 5.3$ & $54.2 \pm 4.7$ & $50.4 \pm 3.5$ & $54.2 \pm 3.8$ & $49.1 \pm 4.2$ \\
\hline Isoleucine & $98 \pm 5.6$ & $89.3 \pm 8.4$ & $92.8 \pm 6.9$ & $95.5 \pm 6.9$ & $95.2 \pm 6.3$ & $92.8 \pm 7.7$ \\
\hline Leucine & $198.1 \pm 9.9$ & $179.6 \pm 17.5$ & $187.2 \pm 14.5$ & $192.5 \pm 12.7$ & $186.6 \pm 13.1$ & $196.1 \pm 12.9$ \\
\hline Lysine & $116.9 \pm 9.5$ & $112.5 \pm 14.9$ & $124.3 \pm 13.8$ & $106.9 \pm 9.7$ & $120.9 \pm 11.4$ & $106.1 \pm 11.6$ \\
\hline Methionine & $26.8 \pm 2.3$ & $28.1 \pm 3.3$ & $31.5 \pm 3.2^{\mathrm{a}}$ & $23.7 \pm 1.9^{b}$ & $28.5 \pm 2.7$ & $25.6 \pm 2.6$ \\
\hline Ornithine & $123.6 \pm 9.8$ & $127.7 \pm 19.9$ & $136.6 \pm 16.4$ & $115.5 \pm 12.4$ & $125.1 \pm 12.8$ & $125.8 \pm 17.1$ \\
\hline Phenylalanine & $104.2 \pm 6.1$ & $92.6 \pm 7.6$ & $98.9 \pm 7.7$ & $99.4 \pm 6.3$ & $99.7 \pm 6.4$ & $98.4 \pm 7.6$ \\
\hline Serine & $860.5 \pm 72.1$ & $752.5 \pm 76.3$ & $697.8 \pm 53.7^{\mathrm{a}}$ & $915 \pm 79.9^{b}$ & $843.7 \pm 64.7$ & $768.7 \pm 90.6$ \\
\hline Taurine & $128.7 \pm 13.5$ & $109.4 \pm 16.1$ & $134.1 \pm 18$ & $108.3 \pm 11$ & $123.5 \pm 12.2$ & $115.6 \pm 18.8$ \\
\hline Threonine & $239.9 \pm 24.8$ & $205.4 \pm 26.7$ & $277.1 \pm 30.7^{a}$ & $179.4 \pm 13.5^{b}$ & $256 \pm 25.5^{\mathrm{a}}$ & $178.4 \pm 18.5^{b}$ \\
\hline Tryptophan & $35.4 \pm 2.3$ & $31.1 \pm 2.8$ & $36.9 \pm 3^{a}$ & $30.6 \pm 1.9^{b}$ & $34.6 \pm 2.6$ & $31.9 \pm 2.4$ \\
\hline Tyrosine & $115.5 \pm 10.8$ & $100.1 \pm 8.9$ & $116.8 \pm 13.1$ & $101.9 \pm 7.3$ & $103 \pm 9.1$ & $117.6 \pm 12.1$ \\
\hline Valine & $256.8 \pm 13.8$ & $218.6 \pm 19.3$ & $262.3 \pm 18^{a}$ & $220.3 \pm 14.3^{b}$ & $244.6 \pm 15.7$ & $233.7 \pm 18.4$ \\
\hline \multicolumn{7}{|c|}{ Agmatine and polyamines } \\
\hline Agmatine & $214.5 \pm 8.5$ & $231.9 \pm 13.7$ & $226.7 \pm 9.6$ & $218 \pm 11.9$ & $225.4 \pm 11.5$ & $219.9 \pm 10.5$ \\
\hline Putrescine & $8.0 \pm 0.8$ & $6.5 \pm 1.1$ & $8.8 \pm 0.9^{a}$ & $6.1 \pm 0.7^{b}$ & $7.9 \pm 0.9$ & $6.6 \pm 1$ \\
\hline Spermidine & $2.0 \pm 0.3$ & $2.0 \pm 0.4$ & $2.5 \pm 0.4$ & $1.5 \pm 0.2$ & $2.1 \pm 0.3$ & $1.8 \pm 0.3$ \\
\hline Spermine & $7.3 \pm 0.9$ & $6.3 \pm 1.1$ & $7.3 \pm 1$ & $6.4 \pm 1$ & $7.3 \pm 1.1$ & $6.1 \pm 0.6$ \\
\hline \multicolumn{7}{|l|}{ Hexose sugars } \\
\hline Glucose & $1934 \pm 212.8$ & $2231 \pm 475.4$ & $1722 \pm 237.7$ & $2369 \pm 374.6$ & $2377 \pm 301.4$ & $1532 \pm 303$ \\
\hline Fructose & $2019 \pm 640.9$ & $3212 \pm 1166$ & $3836 \pm 1260$ & $1437 \pm 225$ & $1973 \pm 640$ & $3277 \pm 1160$ \\
\hline
\end{tabular}

Concentrations of nutrients in fetal plasma out of ewes treated with either CO $(n=14)$ or P4 $(n=10)$, from either singleton $(n=14)$ or twin pregnancies $(n=10)$, and either male $(n=21)$ or female $(n=13)$. Values represent means \pm SEM. Different superscripts within Effect columns are significantly different $(P<0.05)$

pregnancies $(P<0.05)$. Spermine tended to be in greater abundance in fetal plasma from singleton than twin pregnancies, as well as in plasma from male fetuses from a single pregnancy than a male fetus from a twin pregnancy $(P<0.1)$.

Total amounts of polyamines in allantoic and amniotic fluid are summarized in Tables 4 and 5, respectively, and Supplementary Fig. 2. There were no differences in total amounts of polyamines in either allantoic or amniotic fluid due to P4 treatment $(P>0.05)$. In allantoic fluid, there was significantly more agmatine than spermidine, spermine, and putrescine $(P<0.001)$, and male fetuses tended to have greater amounts of agmatine in allantoic fluid than female fetuses $(P<0.1)$. Allantoic fluid associated with female fetuses of twin pregnancies had greater amounts of spermidine than female fetuses of singleton pregnancies $(P<0.05)$. Comparison of allantoic and amniotic fluids indicated that allantoic fluid had more agmatine than amniotic fluid $(P<0.001)$.

In amniotic fluid, putrescine was the least abundant polyamine $(P<0.05)$. Interestingly, agmatine tended to be in greater abundance in amniotic fluid of twin than 
Table 4 Total amounts (concentration $\times$ volume) of amino acids, agmatine, polyamines, and hexose sugars (mg) in allantoic fluid

\begin{tabular}{|c|c|c|c|c|c|c|}
\hline \multirow[b]{3}{*}{ Nutrient } & \multicolumn{6}{|l|}{ Effect } \\
\hline & \multicolumn{2}{|l|}{ Treatment } & \multicolumn{2}{|l|}{ Litter size } & \multicolumn{2}{|l|}{ Fetal sex } \\
\hline & $\mathrm{CO}$ & P4 & Single & Twin & Male & Female \\
\hline \multicolumn{7}{|l|}{ Amino acid } \\
\hline Alanine & $39 \pm 6.1$ & $30.9 \pm 9$ & $40.8 \pm 7.4$ & $31.3 \pm 7.3$ & $40.9 \pm 6.5$ & $25.6 \pm 8.5$ \\
\hline$\beta$-Alanine & $51.2 \pm 12.2$ & $36.4 \pm 9.8$ & $39.2 \pm 14.7$ & $48.6 \pm 9.3$ & $45.3 \pm 8.1$ & $43.6 \pm 17.9$ \\
\hline Arginine & $57.4 \pm 9.8$ & $64.2 \pm 20.6$ & $46.4 \pm 9.3$ & $70.1 \pm 16.4$ & $75.2 \pm 14.4^{\mathrm{a}}$ & $33.2 \pm 10.1^{b}$ \\
\hline Asparagine & $11 \pm 3.7$ & $7.3 \pm 2$ & $9.2 \pm 2$ & $9.5 \pm 3.6$ & $11.48 \pm 3.3^{\mathrm{a}}$ & $5.4 \pm 1.6^{b}$ \\
\hline Aspartate & $4 \pm 0.6$ & $5.7 \pm 0.8$ & $4.7 \pm 0.8$ & $4.8 \pm 0.6$ & $5.3 \pm 0.6$ & $3.8 \pm 0.7$ \\
\hline Citrulline & $16.3 \pm 3.9$ & $8.7 \pm 2.2$ & $14.9 \pm 2.8$ & $11.5 \pm 3.7$ & $15.7 \pm 3.2$ & $7.8 \pm 3.2$ \\
\hline Glutamate & $15.2 \pm 1.6^{\mathrm{a}}$ & $10.8 \pm 1.2^{b}$ & $13.5 \pm 1.5$ & $13.1 \pm 1.5$ & $14.3 \pm 1.1$ & $11.4 \pm 2.2$ \\
\hline Glutamine & $54.5 \pm 10.3$ & $58.1 \pm 15.6$ & $70.1 \pm 12.4$ & $45.4 \pm 12.2$ & $71.3 \pm 11.8^{\mathrm{a}}$ & $29.7 \pm 9.8^{b}$ \\
\hline Glycine & $27.4 \pm 5$ & $29.8 \pm 6.8$ & $30.8 \pm 6.2$ & $26.8 \pm 5.4$ & $35 \pm 5.1^{\mathrm{a}}$ & $16.4 \pm 5.2^{b}$ \\
\hline Histidine & $19.8 \pm 5.9$ & $15.4 \pm 3.6$ & $19.5 \pm 3.1$ & $16.7 \pm 5.9$ & $18.6 \pm 2.7^{\mathrm{a}}$ & $8.2 \pm 2.4^{b}$ \\
\hline Isoleucine & $5.6 \pm 1.9$ & $3.4 \pm 0.9$ & $5.1 \pm 0.9$ & $4.3 \pm 1.8$ & $5.8 \pm 1.6^{\mathrm{a}}$ & $2.4 \pm 0.9^{b}$ \\
\hline Leucine & $12.2 \pm 3.8$ & $7.2 \pm 1.7$ & $10.4 \pm 1.7$ & $9.7 \pm 3.7$ & $9.3 \pm 1.4$ & $5.9 \pm 2$ \\
\hline Lysine & $27.9 \pm 3.9$ & $31.2 \pm 7.4$ & $34.4 \pm 6.2$ & $35 \pm 10.5$ & $41.8 \pm 9.4^{a}$ & $21.9 \pm 5.9^{b}$ \\
\hline Methionine & $4.1 \pm 1.5$ & $3.5 \pm 1$ & $3.3 \pm 0.8$ & $4.2 \pm 1.4$ & $3.4 \pm 0.7$ & $2.3 \pm 0.7$ \\
\hline Ornithine & $11.51 \pm 2.2$ & $16.2 \pm 5.4$ & $17.8 \pm 3.3$ & $10.6 \pm 3.8$ & $14 \pm 3.7$ & $12.9 \pm 3.5$ \\
\hline Phenylalanine & $6.4 \pm 1.6$ & $5 \pm 1.1$ & $6.9 \pm 1$ & $4.9 \pm 1.6$ & $7.2 \pm 1.4^{\mathrm{a}}$ & $3.2 \pm 0.9^{b}$ \\
\hline Serine & $1099 \pm 143.3$ & $998.4 \pm 174.2$ & $908.6 \pm 147.4$ & $1105 \pm 157.6$ & $1219 \pm 103.7^{a}$ & $667 \pm 219.8^{b}$ \\
\hline Taurine & $417.8 \pm 65.1$ & $358.9 \pm 58.7$ & $496.9 \pm 81.9^{a}$ & $318.2 \pm 43.5^{b}$ & $473.2 \pm 58.7^{\mathrm{a}}$ & $242.5 \pm 38.8^{b}$ \\
\hline Threonine & $27 \pm 7.3$ & $24 \pm 6.3$ & $30.6 \pm 7.9$ & $22.2 \pm 6.2$ & $33.8 \pm 6.8^{\mathrm{a}}$ & $10.8 \pm 3.1^{b}$ \\
\hline Tryptophan & $7.6 \pm 1.1$ & $7.9 \pm 1.4$ & $9 \pm 1.1$ & $6.9 \pm 1.2$ & $9.1 \pm 1^{a}$ & $4.8 \pm 1^{b}$ \\
\hline Tyrosine & $14 \pm 4.4$ & $9.1 \pm 3.4$ & $8.1 \pm 1.3$ & $14.4 \pm 4.8$ & $12.8 \pm 3.6$ & $10.1 \pm 5.1$ \\
\hline Valine & $15.6 \pm 3.7$ & $9.5 \pm 2.6$ & $16.8 \pm 3.2$ & $10.2 \pm 3.3$ & $15.4 \pm 3.2$ & $8.2 \pm 3.1$ \\
\hline \multicolumn{7}{|c|}{ Agmatine and polyamines } \\
\hline Agmatine & $5.3 \pm 0.7$ & $5.8 \pm 0.8$ & $6.7 \pm 0.9$ & $4.6 \pm 0.6$ & $6.1 \pm 0.6$ & $4.3 \pm 1.1$ \\
\hline Putrescine & $0.26 \pm 0.04$ & $0.23 \pm 0.04$ & $0.24 \pm 0.03$ & $0.25 \pm 0.05$ & $0.26 \pm 0.02$ & $0.22 \pm 0.07$ \\
\hline Spermidine & $0.006 \pm 0.01$ & $0.06 \pm 0.01$ & $0.051 \pm 0.01$ & $0.076 \pm 0.01$ & $0.086 \pm 0.02^{\mathrm{a}}$ & $0.057 \pm 0.007^{b}$ \\
\hline Spermine & $0.11 \pm 0.01$ & $0.13 \pm 0.02$ & $0.12 \pm 0.01$ & $0.11 \pm 0.02$ & $0.11 \pm 0.01$ & $0.12 \pm 0.02$ \\
\hline \multicolumn{7}{|l|}{ Hexose sugars } \\
\hline Glucose & $11.9 \pm 1.6$ & $10.6 \pm 1.0$ & $12.4 \pm 1.3$ & $10.6 \pm 1.4$ & $11.6 \pm 1$ & $11 \pm 2$ \\
\hline Fructose & $667.6 \pm 144.3$ & $688.7 \pm 117.2$ & $574.7 \pm 87.6$ & $748.4 \pm 148.3$ & $676.4 \pm 93.6$ & $677.7 \pm 212.5$ \\
\hline
\end{tabular}

Total amounts of nutrients in allantoic fluid from ewes treated with either CO $(n=14)$ or P4 $(n=10)$, from either singleton $(n=14)$ or twin pregnancies $(n=10)$, and associated with either male $(n=21)$ or female $(n=13)$ fetuses. Values represent means \pm SEM. Different superscripts within Effect columns are significantly different $(P<0.05)$

singleton pregnancies. Spermidine was more abundant in amniotic fluid associated with male compared to female fetuses $(P<0.01)$. Amniotic fluid of P4-treated ewes had greater abundances of putrescine in singleton pregnancies compared to twin pregnancies $(P<0.05)$.

\section{Glucose and fructose in maternal and fetal plasma,} allantoic fluid, and amniotic fluids

There were no differences in concentrations of glucose or fructose in maternal (Table 2) or fetal plasma (Table
3), nor any difference in total glucose or fructose in allantoic (Table 4) or amniotic fluid (Table 5) due to P4 treatment $(P>0.05)$. Concentrations of glucose and fructose in maternal and fetal plasma were not different due to fetal number or fetal sex $(P>0.05)$. Total amounts of glucose or fructose in allantoic fluid was not affected by fetal number or fetal sex $(P>0.05)$. Total amounts of glucose were greater in amniotic fluid associated with singleton pregnancies than twin pregnancies $(P<0.05)$, but was not different due to 
Table 5 Total amounts (concentration $\times$ volume) of amino acids, agmatine, polyamines, and hexose sugars (mg) in amniotic fluid

\begin{tabular}{|c|c|c|c|c|c|c|}
\hline \multirow[b]{3}{*}{ Nutrient } & \multicolumn{6}{|l|}{ Effect } \\
\hline & \multicolumn{2}{|l|}{ Treatment } & \multicolumn{2}{|l|}{ Litter size } & \multicolumn{2}{|l|}{ Fetal sex } \\
\hline & $\mathrm{CO}$ & P4 & Single & Twin & Male & Female \\
\hline \multicolumn{7}{|l|}{ Amino acid } \\
\hline Alanine & $4.5 \pm 1$ & $8.3 \pm 2.3$ & $5.9 \pm 1.7$ & $6.2 \pm 1.5$ & $5.5 \pm 1.6$ & $7.1 \pm 1.4$ \\
\hline$\beta$-Alanine & $2.0 \pm 0.9$ & $1.5 \pm 0.4$ & $2.6 \pm 1.2$ & $1.2 \pm 0.3$ & $1.2 \pm 0.3$ & $2.7 \pm 1.3$ \\
\hline Arginine & $2.4 \pm 0.6^{\mathrm{a}}$ & $4.2 \pm 0.8^{b}$ & $3.7 \pm 0.9$ & $2.7 \pm 0.6$ & $2.8 \pm 0.7$ & $3.7 \pm 0.8$ \\
\hline Asparagine & $15.4 \pm 3.1$ & $24.4 \pm 5.8$ & $23.8 \pm 5.3$ & $15.9 \pm 3.6$ & $17.1 \pm 4$ & $22.6 \pm 4.8$ \\
\hline Aspartate & $0.60 \pm 0.1$ & $0.82 \pm 0.2$ & $0.83 \pm 0.2$ & $0.59 \pm 0.1$ & $0.57 \pm 0.1$ & $0.89 \pm 0.2$ \\
\hline Citrulline & $1.8 \pm 0.6$ & $4.1 \pm 1.2$ & $2.7 \pm 0.9$ & $2.8 \pm 0.9$ & $2.2 \pm 0.8$ & $3.7 \pm 1$ \\
\hline Glutamate & $6.4 \pm 0.6$ & $7.5 \pm 1.4$ & $7.1 \pm 0.9$ & $6.8 \pm 1$ & $6.7 \pm 0.9$ & $7.2 \pm 1$ \\
\hline Glutamine & $6.9 \pm 1.8$ & $11.1 \pm 3.1$ & $10.1 \pm 3.1$ & $7.6 \pm 1.9$ & $7.3 \pm 2.2$ & $10.9 \pm 2.7$ \\
\hline Glycine & $8.3 \pm 0.6$ & $12.2 \pm 2.6$ & $9 \pm 1.1$ & $10.6 \pm 1.9$ & $8.8 \pm 1.4$ & $11.7 \pm 2.2$ \\
\hline Histidine & $1.3 \pm 0.4$ & $2.2 \pm 0.6$ & $2.2 \pm 0.6$ & $1.3 \pm 0.4$ & $1.5 \pm 0.4$ & $2 \pm 0.5$ \\
\hline Isoleucine & $0.74 \pm 0.3$ & $1.0 \pm 0.4$ & $0.99 \pm 0.5$ & $0.78 \pm 0.3$ & $0.65 \pm 0.3$ & $1.2 \pm 0.5$ \\
\hline Leucine & $3.2 \pm 0.8$ & $4.9 \pm 1.5$ & $4.6 \pm 1.4$ & $3.4 \pm 0.9$ & $3.6 \pm 1$ & $4.4 \pm 1.3$ \\
\hline Lysine & $1.5 \pm 0.4$ & $2.8 \pm 0.8$ & $3.2 \pm 0.9^{\mathrm{a}}$ & $1.2 \pm 0.3^{b}$ & $0.9 \pm 0.7$ & $2.3 \pm 0.6$ \\
\hline Methionine & $0.74 \pm 0.2$ & $0.95 \pm 0.2$ & $0.82 \pm 0.2$ & $0.83 \pm 0.2$ & $0.59 \pm 0.2$ & $1.2 \pm 0.3$ \\
\hline Ornithine & $0.34 \pm 0.1$ & $0.56 \pm 0.2$ & $0.59 \pm 0.2$ & $0.32 \pm 0.1$ & $0.33 \pm 0.1$ & $0.60 \pm 0.2$ \\
\hline Phenylalanine & $0.70 \pm 0.2$ & $1.1 \pm 0.5$ & $0.68 \pm 0.2$ & $1.0 \pm 0.4$ & $0.81 \pm 0.3$ & $1.0 \pm 0.3$ \\
\hline Serine & $36.3 \pm 4.5$ & $41.7 \pm 5.7$ & $37.2 \pm 5.1$ & $39.5 \pm 4.9$ & $38.2 \pm 4.5$ & $39.1 \pm 5.8$ \\
\hline Taurine & $13.4 \pm 3.2$ & $8 \pm 1$ & $16 \pm 4.1$ & $7.6 \pm 1.1$ & $12.1 \pm 2.4$ & $9.5 \pm 3.4$ \\
\hline Threonine & $2.8 \pm 0.7$ & $6.4 \pm 2.1$ & $5.8 \pm 2$ & $3.3 \pm 0.9$ & $4.9 \pm 1.6$ & $3.4 \pm 0.9$ \\
\hline Tryptophan & $0.72 \pm 0.1$ & $0.86 \pm 0.2$ & $1.0 \pm 0.1^{\mathrm{a}}$ & $0.61 \pm 0.2^{b}$ & $0.67 \pm 0.2$ & $0.95 \pm 0.2$ \\
\hline Tyrosine & $1.7 \pm 0.4$ & $2.7 \pm 0.7$ & $2.1 \pm 0.6$ & $2.1 \pm 0.6$ & $1.9 \pm 0.6$ & $2.4 \pm 0.6$ \\
\hline Valine & $1.9 \pm 0.5$ & $3.2 \pm 1$ & $2.3 \pm 0.7$ & $2.4 \pm 0.8$ & $2.2 \pm 0.7$ & $2.9 \pm 0.7$ \\
\hline \multicolumn{7}{|c|}{ Agmatine and polyamines } \\
\hline Agmatine & $0.14 \pm 0.02$ & $0.16 \pm 0.05$ & $0.17 \pm 0.03$ & $0.13 \pm 0.04$ & $0.15 \pm 0.04$ & $0.15 \pm 0.03$ \\
\hline Putrescine & $0.021 \pm 0.002$ & $0.020 \pm 0.004$ & $0.028 \pm 0.003$ & $0.014 \pm 0.002$ & $0.022 \pm 0.004$ & $0.019 \pm 0.003$ \\
\hline Spermidine & $0.12 \pm 0.03$ & $0.26 \pm 0.07$ & $0.17 \pm 0.04$ & $0.19 \pm 0.05$ & $0.10 \pm 0.02^{\mathrm{a}}$ & $0.31 \pm 0.07^{b}$ \\
\hline Spermine & $0.35 \pm 0.1$ & $0.15 \pm 0.04$ & $0.22 \pm 0.07$ & $0.30 \pm 0.1$ & $0.25 \pm 0.07$ & $0.29 \pm 0.1$ \\
\hline \multicolumn{7}{|l|}{ Hexose sugars } \\
\hline Glucose & $5.8 \pm 0.9$ & $5.1 \pm 0.9$ & $6.9 \pm 1^{\mathrm{a}}$ & $4.4 \pm 0.7^{b}$ & $4.5 \pm 0.4$ & $7.2 \pm 1.4$ \\
\hline Fructose & $721.3 \pm 75.2$ & $672 \pm 178$ & $768.6 \pm 134.8$ & $656.9 \pm 106.1$ & $666 \pm 99.8$ & $763 \pm 149.4$ \\
\hline
\end{tabular}

Total amounts of nutrients in amniotic fluid from ewes treated with either CO $(n=14)$ or P4 $(n=10)$, from either singleton $(n=14)$ or twin pregnancies $(n=10)$, and associated with either male $(n=21)$ or female $(n=13)$ fetuses. Values represent means \pm SEM. Different superscripts within Effect columns are significantly different $(P<0.05)$

fetal sex $(P>0.05)$. Total amounts of fructose in amniotic fluid was not different due to fetal number or fetal sex $(P>0.05)$.

A comparison of glucose and fructose was performed (Supplementary Fig. 3). Concentrations of glucose were greater than fructose in maternal plasma, while concentrations of fructose were greater than glucose in fetal plasma $(P<0.001)$. In both allantoic and amniotic fluid, fructose was more abundant than glucose $(P<0.001)$.
Expression of mRNAs in endometria and placentomes Expression of mRNAs for the cationic amino acid transporters for arginine SLC7A1 $(P<0.05)$ and SLC7A2 $(P<$ $0.001)$,glucose transporter $S L C 2 A 1(P<0.05)$, fructose transporter $S L C 2 A 5(P<0.01)$ ornithine decarboxylase $(O D C 1 ; P<0.05)$, and agmatinase (AGMAT; $P<0.01$ ) was greater in endometria from $\mathrm{P} 4$-treated compared to CO-treated ewes (Fig. 1a-g). Expression of AZIN2 mRNA (also known as arginine decarboxylase [ADC]) tended to be greater in endometria from twin 
pregnancies than singleton pregnancies $(P<0.1)$ (Fig. 1h). Expression of SLC6A9 (sodium- and chloridedependent glycine transporter) and SLC1A4 (sodiumdependent neutral amino acid transporter for alanine, serine, cysteine, threonine, and glutamate) mRNAs was not different in endometria from P4-treated and $\mathrm{CO}$ treated $(P>0.1)$ (data not shown). In placentomes, expression of neutral amino acid transporter SLC1A4 $(P<0.01)$, fructose transporter $S L C 2 A 5(P<0.01)$, glucose and fructose transporter $S L C 2 A 8(P<0.01)$, and $O D C 1$ mRNAs was greater in P4-treated compared to CO-treated ewes $(P<0.01)$ (Fig. 2a, d-f). Interestingly, expression of mRNAs for glucose transporters $S L C 2 A 1$ $(P<0.05)$ and $S L C 2 A 3(P<0.01)$ was down-regulated in placentomes of P4-treated ewes (Fig. $2 \mathrm{~b}$ and c). Expression of SLC7A1 $(P<0.05)$, SLC7A2 $(P<0.1), S L C 2 A 1$ $(P<0.01)$, and $S L C 2 A 3(P<0.05)$ mRNAs was greater in placentomes of pregnancies with a singleton fetus compared to pregnancies with twin fetuses (Fig. 2g-j). Intriguingly, expression of SLC6A9 $(P<0.05), S L C 2 A 5$ $(P<0.05)$, and SLC2A8 $(P<0.1)$ mRNA was greater in placentomes associated with female compared male fetuses (Fig. 2k-m). Expression of AZIN2 mRNA in endometria was unaffected by either P4 treatment or fetal sex $(P>0.01)$ (data not shown). Expression of AZIN2 and AGMAT mRNAs in placentomes was unaffected by $\mathrm{P} 4$ treatment $(P>0.1)$ (data not shown).

\section{Localization of proteins in endometria}

Representative images of each protein stained for both $\mathrm{CO}$ and $\mathrm{P} 4$ treatment groups, as well as IgG controls, are shown in Figs. 3, 4, 5, 6 and 7. SLC2A5 protein localized to uterine glandular epithelia, but not uterine luminal or superficial glandular epithelia (Fig. 3). ODC1 protein localized to both uterine luminal epithelia and glandular epithelia (Fig. 4). AZIN2 positive cells were detected in the uterine luminal epithelia and smooth muscle surrounding blood vessels (Fig. 5). Interestingly, the mean percent of glandular epithelia stained for AZIN2 protein was greater $(P<0.05)$ in $P 4$-treated ewes $(22.5 \pm 4.8 \%)$ compared to CO-treated ewes $(4.5 \pm 1.8 \%)$ (Fig. 5) and localized to uterine luminal epithelia in both treatment groups. AZIN2 protein was widely expressed throughout the placentome including caruncular tissue, syncytialized giant cells, and mononuclear cells of the chorioallanois, but not cotyledonary stroma (Fig. 6). Intriguingly, AGMAT protein localized to syncytialized chorioallanotis in the placentome (Fig. 7).

\section{Discussion}

The results of this study indicate that $\mathrm{P} 4$ administration from day 1.5 to day 9 of pregnancy affects abundance of amino acids in placental fluids to 1 ) increase total aspartate in allantoic fluid; 2) decrease total glutamate in allantoic fluid; and 3) increase total arginine in amniotic fluid. This treatment also influenced the expression of

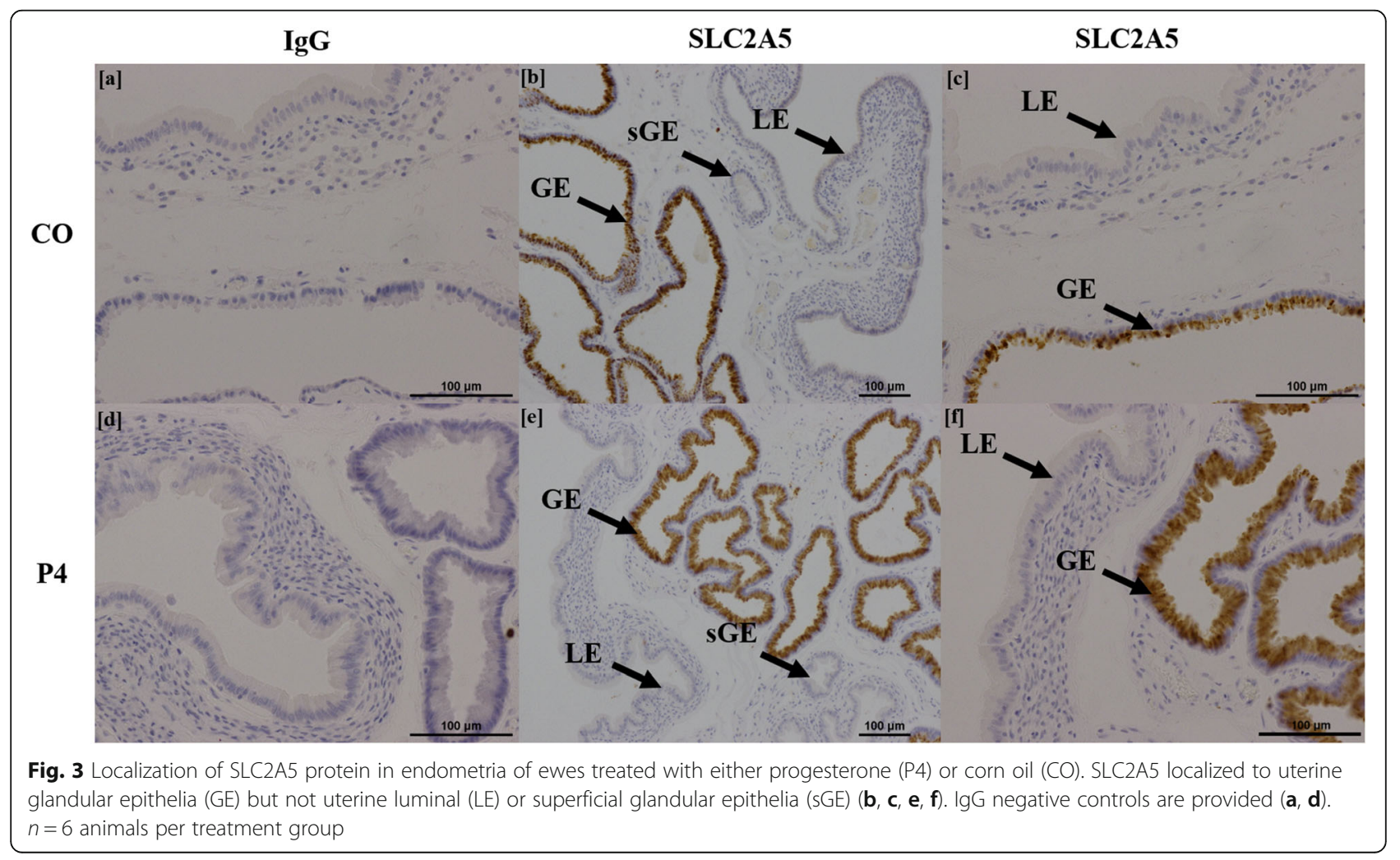




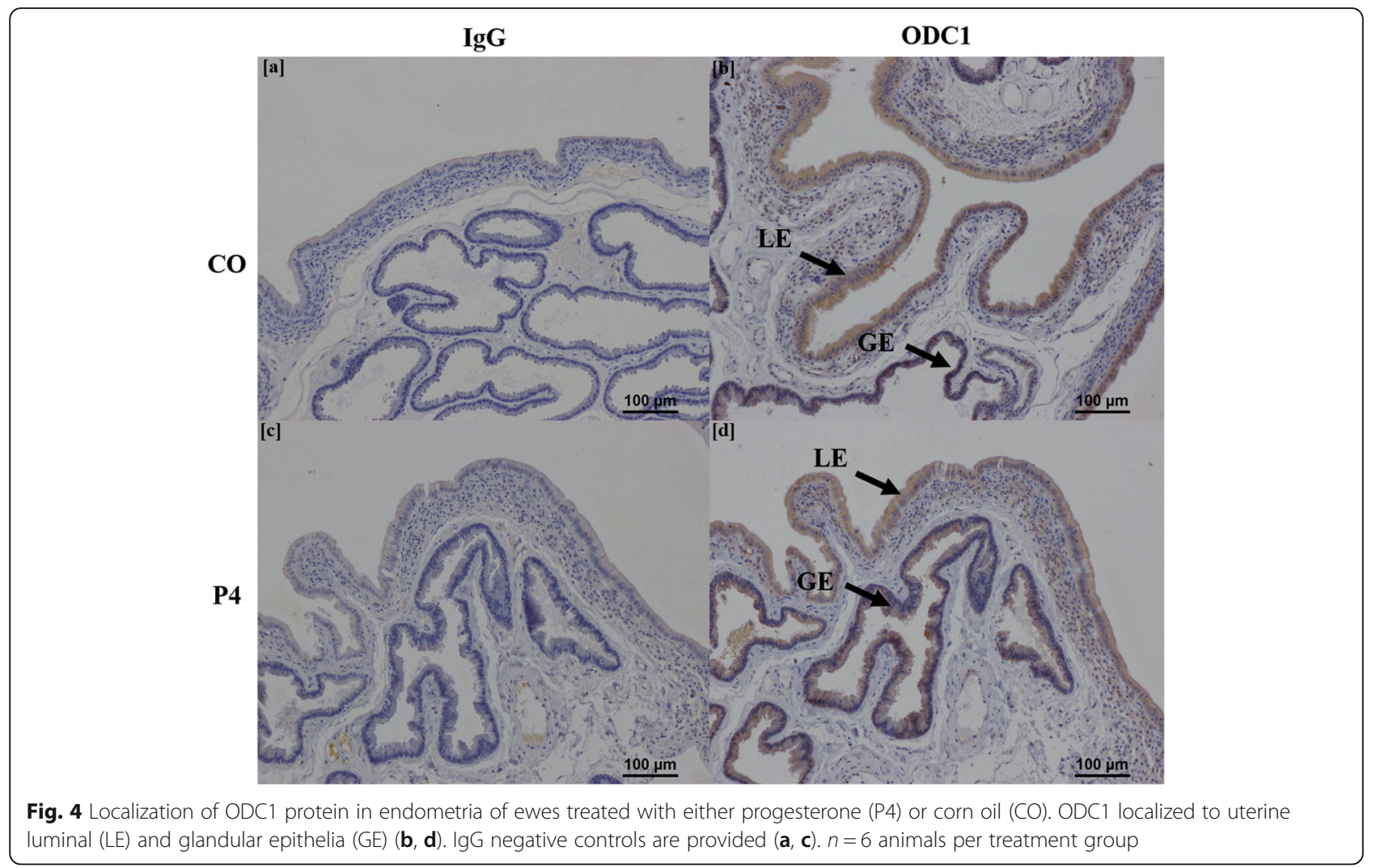

mRNAs in endometrial and placental tissues, suggesting P4-induced modification of these transporters. Previous studies have indicated that progesterone supplementation in early gestation enhances conceptus development $[29,32]$ however in this study, we determined that treatment of ewes with progesterone in early pregnancy does not increase overall fetal or placental growth at day 125 of gestation.

Interestingly, there was a decrease in pregnancy rates from breeding to determination of pregnancy at day 35 of gestation in the P4-treated group. Other studies demonstrate that asynchronous embryo transfers, particularly if

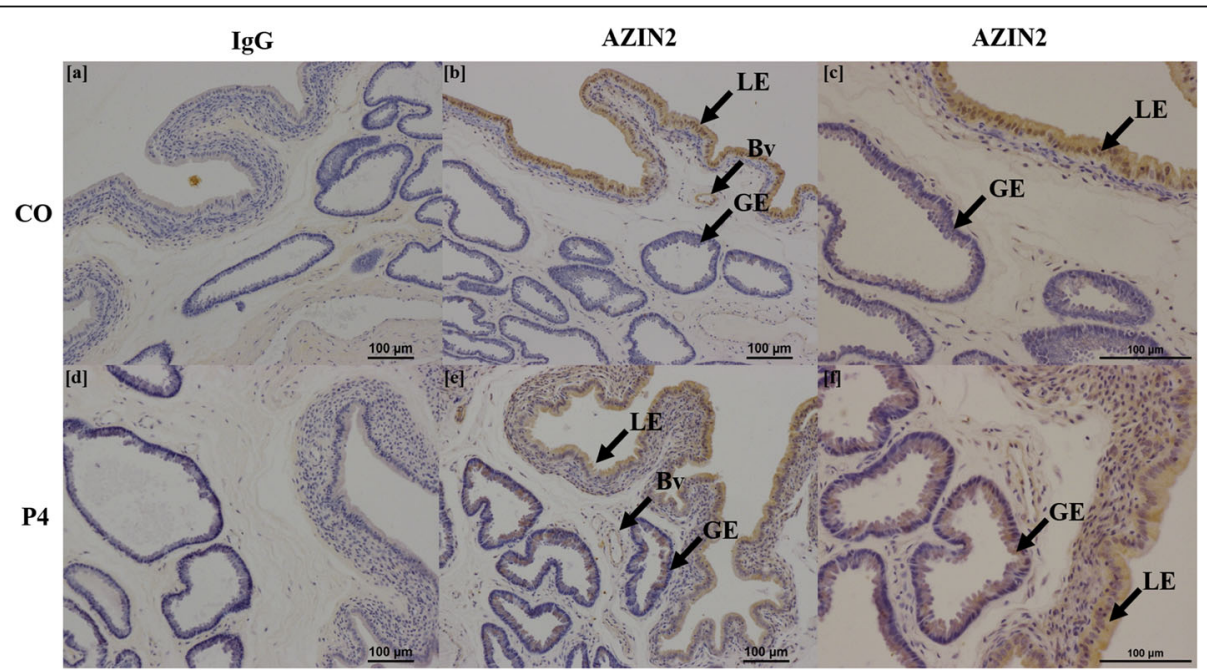

Fig. 5 Localization of AZIN2 protein in endometria of ewes treated with either progesterone (P4) or corn oil (CO). AZIN2 localized to uterine luminal epithelia (LE) in CO-treated ewes (b), whereas in P4-treated ewes localized to both uterine luminal (LE) and glandular epithelia (GE) (d). In both treatment groups, AZIN2 localized to blood vessels (Bv). IgG negative controls are provided (a, c). $n=6$ animals per treatment group 


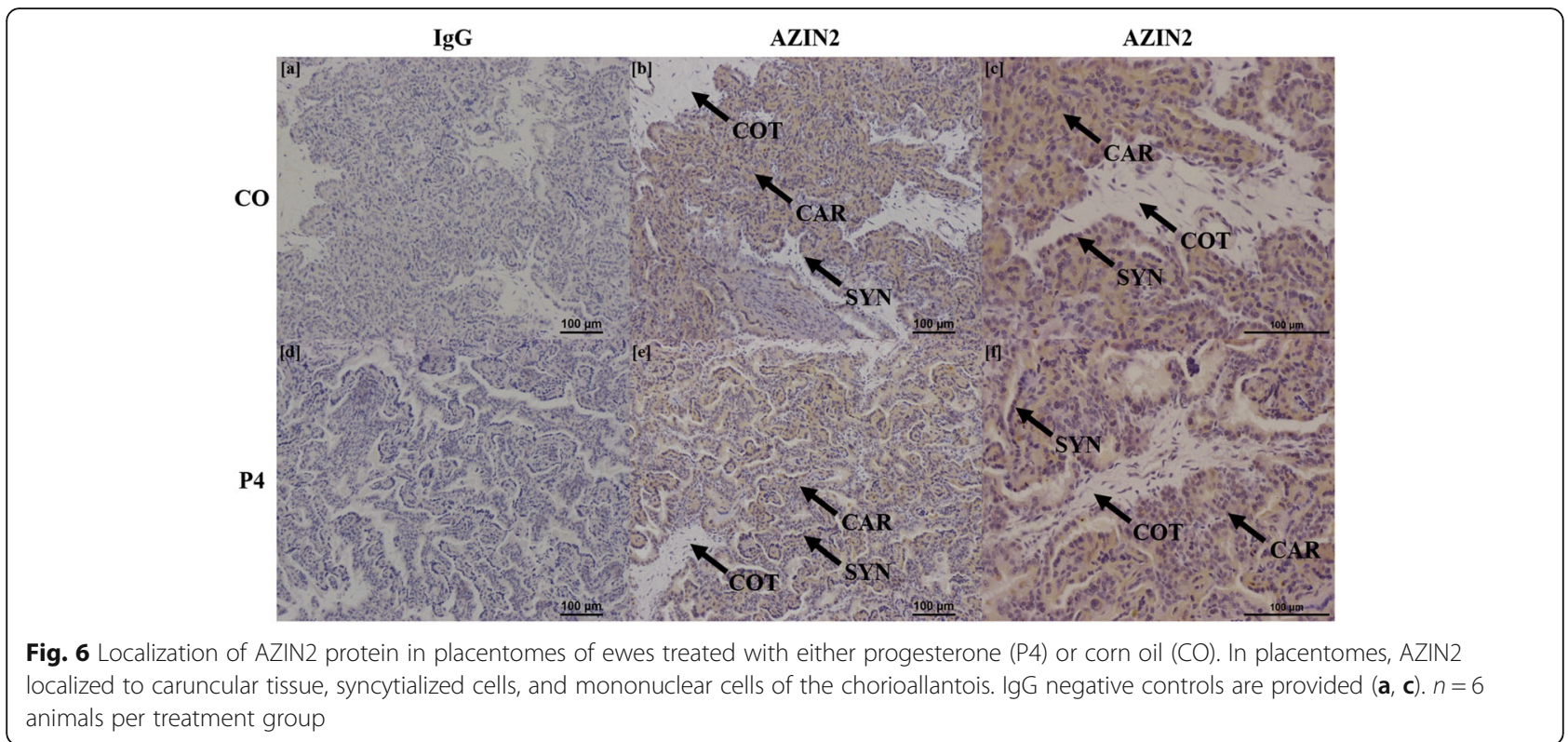

embryos are transferred into a more 'advanced' uterine environment, result in reduced pregnancy rates in ruminants [31, 32, 39, 40]. Supplementation of P4 beginning $36 \mathrm{~h}$ after the onset of estrus advances the P4-induced up- and downregulation of genes in the endometrium to create an advanced uterine environment [29] (and Hoskins et al., unpublished results), which likely explains the decreased pregnancy rates observed in this study and in Hoskins et al., unpublished results.

On day 125 of pregnancy, concentrations of P4 in maternal plasma were not different between treatment groups since the $\mathrm{P} 4$ supplementation occurred 117 days

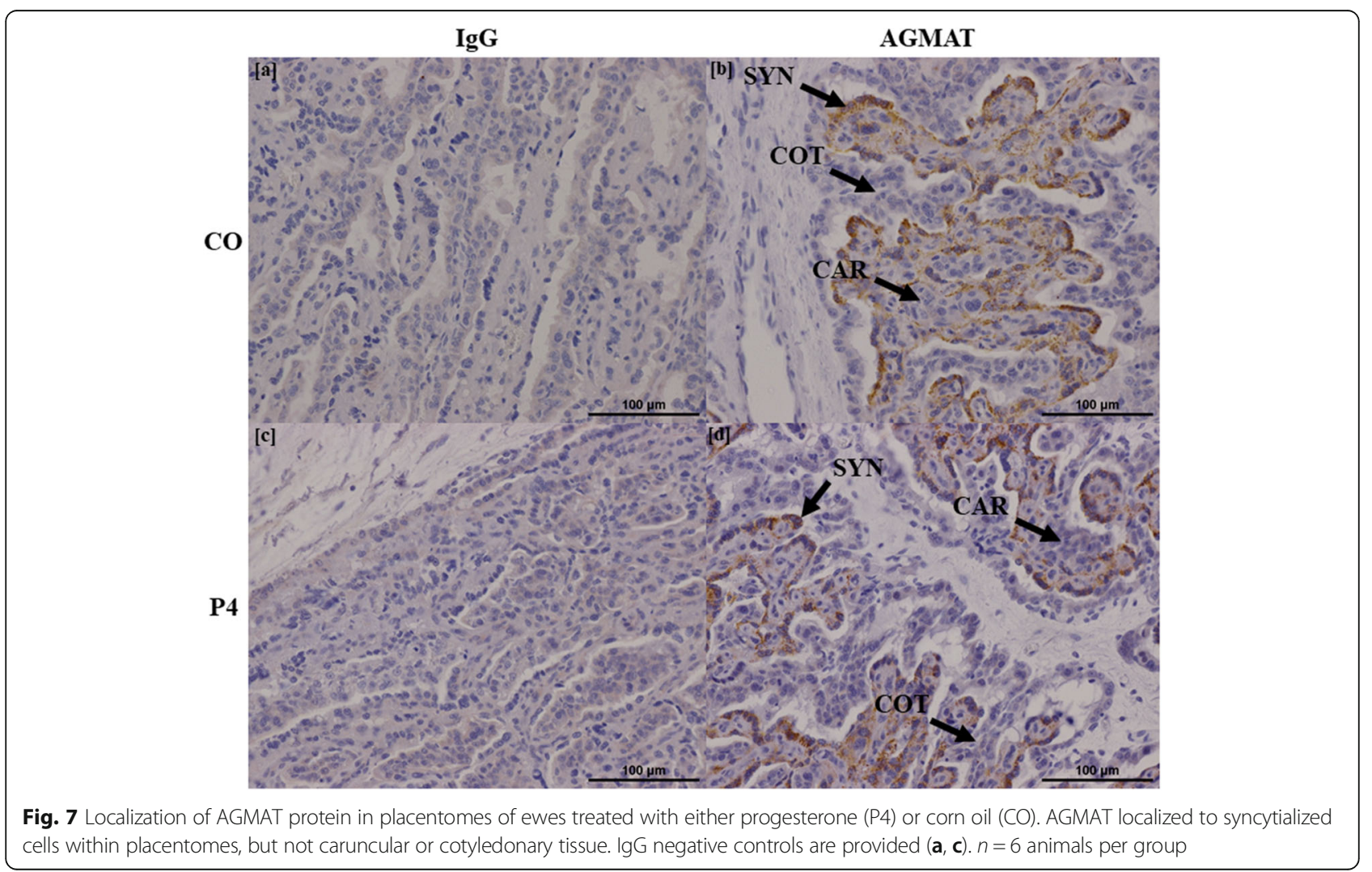


prior to sample collection. While treatment increased levels of $\mathrm{P} 4$ from days 1.5 to 9 of pregnancy (Hoskins et al., unpublished results), $\mathrm{P} 4$ concentrations return to endogenous levels by day 12 of pregnancy, 3 days after the last injection (Hoskins et al., unpublished results). Thus, concentrations of P4 reflected only endogenous levels from the placenta $[41,42]$ and any effects due to treatment at day 125 would have required some 'programming' effects of P4 in the first week of gestation, when P4 was administered.

The relationships between $\mathrm{P} 4$ and the subsequent uterine responses that, in turn, influence the developing conceptus, have been extensively studied [24, 26, 43]. Early exogenous P4 treatment advances conceptus development in sheep [29, 44], cattle [25, 27], and pigs [45]. These effects of P4-induced accelerated conceptus growth were reported to increase fetal weight and crown rump length when assessed at day 76 of gestation in ewes that received exogenous $\mathrm{P} 4$ beginning $36 \mathrm{~h}$ after ovulation [31]. Furthermore, fetuses from ewes treated with P4 early in gestation had greater weights of organs such as the brain and heart, in addition to an increase in the surface area of placental membranes [32]. In the present study, there were no detectable differences in fetal or placental parameters of growth at day 125 of pregnancy due to administration of exogenous P4 in early pregnancy. While our findings are not in agreement with results presented by Kleemann and colleagues $[31,32]$, there are key differences between the two studies. Foremost, in the Kleemann study, tissues were collected on day 76 of pregnancy, which is considered midgestation in sheep. At that stage of development, placental growth is sufficient for ovine fetuses to experience an exponential growth phase [46]. Indeed, while fetal growth continues until parturition, the day to day increases are much less in later stages of gestation than they are in mid-gestation [46]. Thus, although phenotypic differences were not observed at day 125 of gestation, this does not mean that there would not have been phenotypic differences earlier in gestation, or even effects on postnatal programming. Further research could involve the described $\mathrm{P} 4$ treatment and sampling of tissues at multiple time points across gestation, as well as after parturition.

The caruncular LE and the cotyledonary syncytial epithelial cells within the placentome facilitate the transport of nutrients from the maternal circulation into the fetalplacental circulation and placental fluid compartments via membrane proteins that transport and have affinities for specific nutrients [47, 48]. These cells can regulate nutrient delivery to the fetus by altering the distribution and activities of specific transporters [49]. Nutrients transported from the maternal circulation across the utero-placental interface in the form of histotroph [50] are stored in both allantoic fluid and amniotic fluid, acting as nutrient reserves for the fetus throughout gestation [46]. Our next aim was to determine if early P4 treatment affected maternal and placental tissues on a molecular level to gain insight into possible functional changes in these tissues in response to early P4 treatment. One such measurement of functionality is the composition of nutrients within maternal, fetal, and placental fluids that reflect the ability of the endometrium and placenta to transport nutrients to the fetus. Therefore, we determined the profiles of amino acids, polyamines, and hexose sugars in maternal and fetal plasma, as well as allantoic and amniotic fluids.

Amino acids are unequivocally required by the fetus and placenta for proper growth and development, as amino acids provide functional units for synthesis of DNA, RNA, and proteins [14]. Our results were consistent with those reported by others [3] as glycine was the most abundant amino acid in maternal plasma, while serine, glycine, glutamate, and alanine were the most abundant amino acids in fetal plasma. In the present study, all amino acids were more abundant in fetal plasma than in maternal plasma except for arginine and citrulline. Arginine is not only used as a building block for proteins, but it is also a precursor for important nitrogenous substances including polyamines, agmatine (a substrate for synthesis of polyamines), nitric oxide (NO), and creatine [51, 52]. NO is critical for angiogenesis and vasodilation of the placental vasculature [53], while creatine is important for development of muscle and brain, and generation of ATP [51]. Equivalent concentrations of arginine and citrulline (a precursor of arginine) in maternal and fetal plasma, as compared to all the other amino acids assayed, likely indicates extensive utilization of arginine in support of fetal-placental growth.

Polyamines, downstream metabolites of arginine, are important for normal conceptus development as demonstrated by morpholino knockdown of mRNAs of key enzymes and other proteins involved in the metabolism of arginine to polyamines $[35,54,55]$, and the synthesis, secretion, and degradation of polyamines are tightly regulated $[9,56]$. While the abundance of polyamines in maternal or fetal plasma was not influenced by P4 treatment, agmatine, the immediate precursor for polyamines, was more abundant than putrescine, spermidine, and spermine in maternal and fetal plasma, as well as in allantoic fluid. Agmatine may serve as a reservoir of substrate for polyamine synthesis as demands of the fetus and placenta increase. Indeed, fetal plasma had a greater abundance of not only agmatine, but also spermine and putrescine compared to maternal plasma, highlighting the higher demand of fetal-placental tissues for polyamines. 
While total amounts of aspartate in allantoic fluid tended to be greater in P4-treated ewes, the P4-treated ewes had significantly less glutamate in allantoic fluid than their untreated counterparts. Both aspartate and glutamate are involved in the catabolism of arginine and proline [57] and regulation of the cellular redox state and glycolysis $[51,58]$. Interestingly, total amounts of arginine were greater in amniotic fluid of P4-treated ewes, suggesting that P4 may have influenced metabolism and delivery of amino acids from maternal plasma into placental fluid compartments. Indeed, in our study, P4 treatment up-regulated the expression of mRNAs for SLC7A1 and SLC7A2 in the endometrium, which implies an increased regulation of the transport of cationic amino acids such as arginine through the SLC7 family of transporters [59]. Further, P4-treated ewes had greater expression of mRNAs for AGMAT, a gene encoding agmatinase that is an enzyme that converts agmatine to putrescine that is then metabolized to spermidine and spermine [35], in the endometrium and $O D C 1$, a gene encoding ornithine decarboxylase that converts ornithine to putrescine [60], in both the endometrium and placentomes. This suggests increased metabolism of arginine to polyamines for utilization by the fetus and placenta. Moreover, there was a trend for decreased spermidine in amniotic fluid of P4-treated ewes, which may represent increased utilization of spermidine by the fetus. Interestingly, P4 treatment of ewes resulted in an increased expression of AZIN2 protein in the uterine GE compared to CO-treated ewes, suggesting that polyamine synthesis is regulated in some part by $\mathrm{P} 4$, and the GE of these animals metabolize arginine via both ODC1- and AZIN2-AGMAT-pathways. Differential localization of the enzymes responsible for synthesis of polyamines highlights the synergy of specific cell types to ensure polyamine delivery to the placenta and fetus.

Expression of mRNAs for SLC1A4 (neutral amino acid transporter [61]) was up-regulated in placentomes of P4treated ewes, implying increased regulation of transport of amino acids such as alanine, serine, cysteine, and threonine across the placenta. While the amounts of these amino acids were not different in maternal, fetal, or placental fluids between treatment groups, there is evidence that shows that the placenta itself can utilize serine as a methyl donor for synthesis of purines and thymidine for one-carbon metabolism, and alanine, serine, cysteine, and threonine can be utilized as substrates for gluconeogenesis and other metabolic pathways important for growth and development of the conceptus [14, 62, 63].

Glucose is the primary substrate for synthesis of ATP in most cell types [14] and other metabolic pathways, and is essential for growth and development of the fetalplacental unit in humans [64], rodents [65], and livestock species [66, 67]. P4 administration affects the expression of nutrient transporters, notably those that transport glucose into the uterine lumen [30, 68]. SLC2A1 (ubiquitous facilitative glucose transporter) mRNA is induced by $\mathrm{P} 4$ and further stimulated by IFNT [30, 68], and SLC2A3 (high affinity facilitative glucose transporter) mRNA is unique to conceptus trophectoderm in early pregnancy and the placenta in mid- to late-pregnancy $[68,69]$. In the present study, P4-treated ewes had greater expression of mRNAs for $S L C 2 A 1$ in the endometrium. This suggests increased glucose transport from the maternal circulation into the fetal-placental circulation for use, either by the placenta directly, transport into the fetal circulation, or transport across the chorioallantois into the allantoic fluid. Conversely, expression of mRNAs for $S L C 2 A 1$ and $S L C 2 A 3$ was lower in placentomes of P4-treated ewes. A potential explanation for this alteration could be that placentas from P4-treated ewes actively downregulated these transporters in the placentome due to increased glucose trafficking in the interplacentomal regions of the uterineplacental interface by the $S L C 2 A 1$ transporter.

It has been demonstrated that concentrations of glucose in maternal plasma are relatively constant throughout gestation, even as the demands of the fetal-placental unit for glucose increase [46, 70], assuming ewes are well fed and not nutritionally challenged [71, 72]. Given these findings, it is perhaps unsurprising that concentrations of glucose in maternal plasma were not influenced by treatment, the number of fetuses, or fetal sex, as the ewes in this study were not nutrient restricted. Total amounts of glucose in allantoic and amniotic fluid were not different between P4- and CO-treated ewes, despite an up-regulation in $S L C 2 A 1$ mRNA in the endometria of P4-treated ewes. This may have been due to increased placental or fetal catabolism of glucose by fetal-placental tissues in P4-treated ewes during pregnancy. Glucose that passes through the fetal-placental circulation may undergo rapid catabolism to produce ATP [73], be converted to fructose which is sequestered within placental tissue and fluids $[74,75]$, or be metabolized via the pentose phosphate pathway $[15,21,76]$, hexosamine biosynthesis pathway [20,77], or serinogenesis pathway for one-carbon metabolism [22, 78].

Fructose is the most abundant hexose sugar in fetal blood and placental fluids of ungulates and cetaceans $[18,79]$, and is considered a 'sequestered' sugar due to the lack of expression of a transporter to return it back into the maternal circulation [74, 75]. While fructose contributes little to gluconeogenesis and production of ATP $[80,81]$, it can be used in the hexosamine biosynthesis pathway for the synthesis of glycosaminoglycans such as hyaluronic acid in trophectoderm cells of pigs [21] and sheep [20]. Concentrations of fructose in fetal plasma were significantly greater than those in maternal 
plasma, which is consistent with results from other studies $[18,79]$. In the present study, the expression of mRNAs for SLC2A5 (transporter of fructose) and $S L C 2 A 8$ (transporter of both glucose and fructose) was greater in both endometria and placentomes of P4treated ewes, but there were no differences in total amounts of fructose in allantoic or amniotic fluid. Potentially, the placentae or fetuses of these P4-treated ewes utilized fructose for hexosamine biosynthesis, which integrates metabolism of amino acids such as glutamine [14], and also stimulates expression of the mechanistic target of rapamycin (mTOR) that activates enzymes for generation of serine for one-carbon metabolism [20, 82]. Indeed, there were differences in concentrations of amino acids in both allantoic and amniotic fluid. Interestingly, the SLC2A5 transporter localized exclusively to uterine glandular epithelia, which indicates that fructose is secreted in histotroph and collects in placental areolae for uptake, rather than directly transported across uterine luminal epithelia to the chorioallantois.

In this study, male fetuses had increased abundances of several amino acids in allantoic fluid and fetal plasma. As most research indicates that male fetuses grow at a faster rate than females $[83,84]$, the placentas of male fetuses may have been actively transporting and storing greater amounts of amino acids in placental fluids in anticipation for greater demands for fetal growth. More interestingly, placentomes associated with female fetuses had greater expression of the glycine transporter SLC6A9 than placentomes of male fetuses, suggesting increased regulation of transport of glycine in these placentae. Although glycine was present in greater amounts in allantoic fluid associated with male fetuses, placentae of female fetuses may utilize greater amounts of glycine, rather than storing it in allantoic fluid. It has been suggested that perturbations in placental development in the first trimester of pregnancy affect females more than males [84], and that placental tissues express genes in a sexually dimorphic manner [85]. In humans, a pathway analysis revealed sex-biased genes involved in mTOR signaling in placentae [86], a biologically relevant pathway within the placenta $[77,87]$. mTOR signaling activates enzymes for generation of serine for one-carbon metabolism [22, 51], and also integrates metabolism of amino acids and hexose sugars (particularly fructose) to regulate nutrient and growth signaling within the fetalplacental unit $[20,77,87]$. In accordance with this, greater expression of the fructose transporters SLC2A5 and $S L C 2 A 8$ were observed in placentomes of female fetuses, suggesting that placentae of female fetuses had a greater capacity to transport fructose. Further studies are required to determine sex-specific pathways of amino acid utilization within the fetal-placental unit.

\section{Conclusions}

Collectively, results of the present study identified P4induced modifications in the endometrium and placenta that were influenced by treatment of ewes with P4 in early gestation, even before signaling for maternal recognition of pregnancy (as discussed by the companion paper to this study, Hoskins et al. 2020). These modifications influenced the expression of mRNAs for nutrient transporters in fetal-placental tissues, the expression of a key protein in uterine glandular epithelia, and composition of placental fluids, thereby influencing the pool of nutrients available to support development of the fetalplacental unit as pregnancy progressed. Further studies are necessary to determine how treatment with $\mathrm{P} 4$ in early gestation affects developing fetal tissues, and how those effects may influence neonatal performance. Characterizing how exogenous steroids affect the gestational environment ultimately aids in our understanding of how hormonal regimens, used either in animal production or in human medicine, influence development of the conceptus and successful outcomes of pregnancy.

\section{Supplementary Information}

The online version contains supplementary material available at https://doi. org/10.1186/s40104-021-00567-1.

Additional file 1: Supplementary Fig. 1 Relative abundances of amino acids in maternal and fetal plasma $(\mathrm{a}, \mathrm{b})$ and placental fluids $(\mathrm{c}, \mathrm{d})$. Amino acids in plasma are expressed as concentrations (nmol/mL), and amino acids in placental fluids are expressed as total amounts

(concentration $\times$ volume). Glutamate, glycine, and alanine were most abundant in maternal plasma (a), while glutamate, serine, glycine, and alanine were most abundant in fetal plasma (b). All amino acids, except for arginine and citrulline, were more abundant in fetal plasma than maternal plasma. The most abundant amino acids in allantoic fluid were serine and taurine (c). The most abundant amino acids in amniotic fluid were asparagine and serine (d).

Additional file 2: Supplementary Fig. 2 Relative abundances of polyamines in maternal and fetal plasma $(a, b)$ and placental fluids. Agmatine and polyamines in plasma are expressed as concentrations $(\mathrm{nmol} / \mathrm{mL})$, and expressed as total amounts (concentration $\times$ volume) in placental fluids. Agmatine was most abundant in the plasma of both ewes and fetuses $(a, b)$. Similarly, agmatine was most abundant in allantoic fluid (c). In amniotic fluid, total amounts of agmatine were similar to those for polyamines, except for putrescine, which was least abundant (d).

Additional file 3: Supplementary Fig. 3 Relative abundances of hexose sugars in maternal and fetal plasma $(a, b)$ and placental fluids $(c, d)$. Glucose and fructose concentrations in plasma are expressed as concentrations ( $\mu \mathrm{mol} /$ $\mathrm{L}$ ), and in placental fluids are expressed as total amounts (concentration $\times$ volume). There were greater concentrations of glucose than fructose in maternal plasma (a), in contrast to fetal plasma (b) which had greater concentrations of fructose compared to glucose. Similarly, both allantoic fluid (c) and amniotic fluid (d) had greater total amounts of fructose compared to glucose. Mean values and SEM are presented. $n=5-9$ samples per group.

Additional file 4: Supplementary Table 1. Primers used for real-time qPCR

Additional file 5: Supplementary Table 2. Antibodies used for immunohistochemistry 
Additional file 6: Supplementary Table 3. A summary of measurements affected by progesterone (P4) treatment, pregnancy type, and fetal sex. Includes interactions that are significant $(P<0.05)$ or tend to be significant $(P<0.1)$.

\section{Abbreviations}

ANOVA: Analysis of variance; ATP: Adenosine triphosphate; CO: Corn oil $\mathrm{CT}$ : Cycle threshold; GE: Uterine glandular epithelia; HPLC: High performance liquid chromatography; IFNT: Interferon-tau; LE: Uterine luminal epithelial epithelia; MTOR: Mechanistic target of rapamycin; NADPH: Nicotinamide adenine dinucleotide phosphate hydrogen; NO: Nitric oxide; OPA: OPhthaldialdehyde; P4: Progesterone; PBS: Phosphate buffered saline; RIN: RNA integrity number; SEM: Standard error of the mean; sGE: Uterine superficial glandular epithelia; qPCR: Quantitative polymerase chain reaction

\section{Acknowledgements}

The contributions of undergraduate students, graduate students, postdoctoral research associates, and faculty of Texas A\&M University to this study are gratefully acknowledged. The authors would also like to thank the animal research unit staff for their assistance.

\section{Authors' contributions}

The experiments were planned by FWB, GW, and GJ and executed by $\mathrm{KH}$ with assistance from EH, CS, RM, KD, MS, and HS. The first draft of the manuscript was written by KH and FWB and was edited by GW, GJ, MS, CS, $\mathrm{EH}$, and RM. The final version of the manuscript was prepared by $\mathrm{KH}$ and FWB. The authors read and approved the final manuscript.

\section{Funding}

This research was supported by Agriculture and Food Research Initiative Competitive Grant no. 2016-67015-24958 from the USDA National Institute of Food and Agriculture.

Grant support: This research was supported by Agriculture and Food Research Initiative Competitive Grant no. 2016-67015-24958 from the USDA National Institute of Food and Agriculture.

\section{Availability of data and materials}

The datasets generated in the current study can be made available from the corresponding author upon reasonable request.

\section{Ethics approval and consent to participate}

All experimental procedures followed the Guide for the Care and Use of Agriculture Animals in Research and Teaching and approved by the Institutional Animal Care and Use Committee of Texas A\&M University (Reference Number: 083787). There was no use of human participants, data, or tissues.

\section{Consent for publication}

Not applicable.

\section{Competing interests}

The authors have no conflict of interest to declare.

\section{Author details}

'Department of Animal Science, Texas A\&M University, College Station, TX 77843-2471, USA. ${ }^{2}$ Department of Veterinary Integrative Biosciences, Texas A\&M University, College Station, TX 77843, USA.

Received: 7 October 2020 Accepted: 2 February 2021

Published online: 08 April 2021

\section{References}

1. Bazer FW, Wu G, Johnson GA, Kim J, Song G. Uterine histotroph and conceptus development: select nutrients and secreted phosphoprotein 1 affect mechanistic target of rapamycin cell signaling in ewes. Biol Reprod. 2011:85:1094-107.

2. Bazer FW. Uterine protein secretions: relationship to development of the conceptus. J Anim Sci. 1975;41:1376-82.

3. Kwon H, Spencer TE, Bazer FW, Wu G. Developmental changes of amino acids in ovine fetal fluids. Biol Reprod. 2003;68:1813-20.
4. Fozard J, Part M, Prakash N, Grove J, Schehter P, Sjoerdsma A, et al. LOrnithine decarboxylase: An essential role in early mammalian embryogenesis. Science (80- ). 1980;208:505-8.

5. Wu G, Bazer FW, Wallace JM, Spencer TE. Intrauterine growth retardation: implications for the animal sciences. J Anim Sci. 2006;84:2316-37.

6. Henningsson A, Henningsson S, Nilsson O. Diamines and polyamines in mammalian reproduction. Adv Polyam Res. 1982;4:193-207.

7. Kim J-Y, Burghardt RC, Wu G, Johnson GA, Spencer TE, Bazer FW. Select nutrients in the ovine uterine lumen. VIII. Arginine stimulates proliferation of ovine trophectoderm cells through MTOR-RPS6K-RPS6 signaling cascade and synthesis of nitric oxide and polyamines. Biol Reprod. 2011;84:70-8.

8. Wu G, Bazer F, Cudd T, Meininger C, Spencer T. Maternal nutrition and fetal development. J Nutr. 2004;21:69-72.

9. Igarashi K, Kashiwagi K. Polyamines: mysterious modulators of cellular functions. Biochem Biophys Res Commun. 2000;271:559-64.

10. Coburn RF. Polyamine effects on cell function: possible central role of plasma membrane PI(4,5)P2. J Cell Physiol. 2009;221:544-51.

11. DeHart GW, Jin T, McCloskey DE, Pegg AE, Sheppard D. The a9 $\beta 1$ integrin enhances cell migration by polyamine-mediated modulation of an inward-rectifier potassium channel. Proc Natl Acad Sci U S A. 2008; 105:7188-93.

12. Santos MF, Viar MJ, McCormack SA, Johnson LR. Polyamines are important for attachment of IEC-6 cells to extracellular matrix. Am J Physiol Gastrointest Liver Physiol. 1997;273:175-83.

13. Lefèvre PLC, Palin MF, Murphy BD. Polyamines on the reproductive landscape. Endocr Rev. 2011;32:694-712.

14. Wu G. Principles of animal nutrition. Boca Raton: CRC Press; 2018

15. Jones CT, Rolph TP. Metabolism during fetal life: a functional assessment of metabolic development. Physiol Rev. 1985;65:357-430.

16. Marconi AM, Cetin I, Davoli E, Baggiani AM, Fanelli R, Fennessey PV, et al. An evaluation of fetal glucogenesis in intrauterine growth-retarded pregnancies. Metabolism. 1993;42:860-4.

17. Leonce J, Brockton N, Robinson S, Venkatesan S, Bannister P, Raman V, et al. Glucose production in the human placenta. Placenta. 2006;27:103-8.

18. Bacon JS, Bell DJ. Fructose and glucose in the blood of the foetal sheep. Biochem J. 1948:42:397-405.

19. Barklay $H$, Haas $P$, Huggett $A$, King G, Rowley D. The sugar of the foetal blood, the amniotic and allantoic fluids. J Physiol. 1949;109:98-102.

20. Wang X, Li D, Wu G, Bazer FW. Functional roles of fructose: crosstalk between O-linked glycosylation and phosphorylation of Akt-TSC2-MTOR cell signaling cascade in ovine trophectoderm cells. Biol Reprod. 2016;95:102.

21. Kim J, Song G, Wu G, Bazer FW. Functional roles of fructose. Proc Natl Acad Sci U S A. 2012;109:1619-28

22. Ben-Sahra I, Hoxhaj G, Ricoult SJH, Asara JM, Manning BD. mTORC1 induces purine synthesis through control of the mitochondrial tetrahydrofolate cycle. Science (80- ). 2016;351:728-33.

23. White CE, Piper EL, Noland PR, Daniels LB. Fructose utilization for nucleic acid synthesis in the fetal pig. J Anim Sci. 1982;55:73-6.

24. Mann GE, Lamming GE. Relationship between maternal endocrine environment, early embryo development and inhibition of the luteolytic mechanism in cows. Reproduction. 2001;121:175-80.

25. Garrett JE, Geisert RD, Zavy MT, Morgan GL. Evidence for maternal regulation of early conceptus growth and development in beef cattle. Reprod Fertil. 1988;84:437-46.

26. Mann GE, Lamming GE. The influence of progesterone during early pregnancy in cattle. Reprod Domest Anim. 1999;34:269-74.

27. Mann GE, Fray MD, Lamming GE. Effects of time of progesterone supplementation on embryo development and interferon-t production in the cow. Vet J. 2006;171:500-3.

28. Satterfield MC, Hayashi K, Song G, Black SG, Bazer FW, Spencer TE. Progesterone regulates FGF10, MET, IGFBP1, and IGFBP3 in the endometrium of the ovine uterus. Biol Reprod. 2008;79:1226-36.

29. Satterfield MC, Bazer FW, Spencer TE. Progesterone regulation of preimplantation conceptus growth and galectin 15 (LGALS15) in the ovine uterus. Biol Reprod. 2006;75:289-96.

30. Satterfield MC, Gao H, Li X, Wu G, Johnson GA, Spencer TE, et al. Select nutrients and their associated transporters are increased in the ovine uterus following early progesterone administration. Biol Reprod. 2010;82:224-31.

31. Kleemann DO, Walker SK, Seamark RF. Enhanced fetal growth in sheep administered progesterone during the first three days of pregnancy. $J$ Reprod Fertil. 1994;102:411-7. 
32. Kleemann DO, Walker SK, Hartwich KM, Fong L, Seamark RF, Robinson JS, et al. Fetoplacental growth in sheep administered progesterone during the first three days of pregnancy. Placenta. 2001;22:14-23.

33. NRC. 6th ed. Washington DC: National Acedemy of Sciences; 1985.

34. Scarpa JO, O’Neil MM, Cardoso RC, Stanko RL, Williams GL. Ovarian follicular and luteal characteristics in Bos indicus-influenced beef cows using prostaglandin $\mathrm{F} 2 \mathrm{a}$ with or without $\mathrm{GnRH}$ at the onset of the 5-day $\mathrm{CO}$ synch + controlled internal drug release (CIDR) protocol. Anim Reprod Sci Elsevier. 2019;204:1-9.

35. Wang X, Ying W, Dunlap KA, Lin G, Satterfield MC, Burghardt RC, et al. Arginine decarboxylase and agmatinase: an alternative pathway for de novo biosynthesis of polyamines for development of mammalian conceptuses. Biol Reprod. 2014;90:1-15.

36. Dai Z, Wu Z, Wang J, Wang X, Jia S, Bazer FW, et al. Analysis of polyamines in biological samples by HPLC involving pre-column derivatization with ophthalaldehyde and N-acetyl-L-cysteine. Amino Acids. 2014;46:1557-64.

37. Wu G, Davis PK, Flynn NE, Knabe DA, Davidson JT. Endogenous synthesis of arginine plays an important role in maintaining arginine homeostasis in postweaning growing pigs. J Nutr. 1997;127:2342-9.

38. Vermeulen J, Derveaux S, Lefever S, De Smet E, De Preter K, Yigit N, et al. RNA pre-amplification enables large-scale RT-qPCR gene-expression studies on limiting sample amounts. BMC Res Notes. 2009;2:1-9.

39. Wilmut I, Sales DI. Effect of an asynchronous environment on embryonic development in sheep. J Reprod Fertil. 1981;61:179-84.

40. Van Cleeff J, Macmillian K, Drost M, Lucy M, Thatcher W. Effects of administering progsterone at selected intervals after insemination of synchronized heifers on pregnancy rates and resynchronization to returns to service. Theriogenology. 1996;46:1117-30.

41. Bassett J, Oxborrow T, Smith I, Thornburn G. The concentration of progesterone in the peripheral plasma of the pregnant ewe. J Endocrinol. 1969:45:449-57.

42. Thorbum G, Bassett J, Smith I. Progesterone concentration in peripheral plasma of sheep during estrous cycle. J Endocrinol. 1969;45:459-69.

43. Ashworth CJ, Bazer FW. Changes in ovine conceptus and endometrial function following asynchronus embryo transfer or administration of progesterone. Biol Reprod. 1989;40:425-33.

44. Fermin LM, Pain SJ, Gedye KR, Morel PCH, Kenyon PR, Blair HT. Timing of exogenous progesterone administration is critical for embryo development and uterine gene expression in an ovine model of maternal constraint. Reprod Fertil Dev. 2018;30:1699-712.

45. Muro BBD, Carnevale RF, Leal DF, Torres MA, Mendonça MV, Nakasone DH, et al. Supplemental progesterone during early pregnancy exerts divergent responses on embryonic characteristics in sows and gilts. Animal. 2020;14: 1234-40.

46. Bazer FW, Spencer TE, Thatcher WW. Growth and development of the ovine conceptus. J Anim Sci. 2012;90:159-70.

47. Bell AW, Ehrhardt RA. Regulation of placental nutrient transport and implications for fetal growth. Nutr Res Rev. 2002;15:211-30.

48. Enders AC, Carter AM. Comparative placentation: some interesting modifications for histotrophic nutrition. Placenta. 2006;27:11-6.

49. Brett K, Ferraro Z, Yockell-Lelievre J, Gruslin A, Adamo K. Maternal-fetal nutrient transport in pregnancy pathologies: the role of the placenta. Int J Mol Sci. 2014;15:16153-85.

50. Spencer T, Bazer F. Uterine and placental factors regulating conceptus growth in domestic animals. J Anim Sci. 2004;82(E.Supp):E4-13.

51. Wu G. Amino acids: metabolism, functions, and nutrition. Amino Acids. 2009;37:1-17.

52. Wu G, Bazer FW, Satterfield MC, Li X, Wang X, Johnson GA, et al. Impacts of arginine nutrition on embryonic and fetal development in mammals. Amino Acids. 2013:45:241-56.

53. Reynolds LP, Redmer DA. Angiogenesis in the placenta. Biol Reprod. 2001; 64:1033-40.

54. Wang X, Frank JW, Little DR, Dunlap KA, Satterfield MC, Burghardt RC, et al, Functional role of arginine during the peri-implantation period of pregnancy. I. Consequences of loss of function of arginine transporter SLC7A1 mRNA in ovine conceptus trophectoderm. FASEB J. 2014;28: 2852-63.

55. Wang X, Burghardt RC, Romero JJ, Hansen TR, Wu G, Bazer FW. Functional roles of arginine during the peri-implantation period of pregnancy. III. Arginine stimulates proliferation and interferon tau production by ovine trophectoderm cells via nitric oxide and polyamine-TSC2-MTOR signaling pathways. Biol Reprod. 2015;92:1-17.

56. Igarashi K, Kashiwagi K. Modulation of cellular function by polyamines. Int J Biochem Cell Biol. 2010;42:39-51.

57. Wu G. Amino acids: biochemistry and nutrition. 1st ed. Boca Raton: CRC Press; 2013.

58. Brosnan JT. Glutamate, at the interface between amino acid and carbohydrate metabolism. J Nutr. 2000;130:988S-90S.

59. Closs El, Simon A, Vékony N, Rotmann A. Plasma membrane transporters for arginine. J Nutr. 2004;134:2752S-9S.

60. Kwon H, Wu G, Bazer FW, Spencer TE. Developmental changes in polyamine levels and synthesis in the ovine conceptus. Biol Reprod. 2003;69:1626-34.

61. Regnault TRH, De Vrijer B, Battaglia FC. Transport and metabolism of amino acids in placenta. Endocrine. 2002;19:23-41.

62. Snell K, Fell DA, Snell D. Metabolic control analysis of mammalian serine metabolism. Adv Enzym Regul. 1990;30:13-32.

63. Kalhan SC. One carbon metabolism in pregnancy: impact on maternal, fetal and neonatal health. Mol Cell Endocrinol Elsevier Ireland Ltd. 2016; 435:48-60.

64. Villee CA. Regulation of blood glucose in the human fetus. J Appl Physiol. 1953:5:437-44

65. Zhou J, Bondy CA. Placental glucose transporter gene expression and metabolism in the rat. J Clin Invest. 1993;91:845-52.

66. Hay WW. Placental-fetal glucose exchange and fetal glucose metabolism. Trans Am Clin Climatol Assoc. 2006;117:321-40.

67. Fowden AL, Forhead AJ, Silver M, Macdonald AA. Glucose, lactate and oxygen metabolism in the fetal pig during late gestation. Exp Physiol. 1997;82:171-82.

68. Gao H, Wu G, Spencer TE, Johnson GA, Bazer FW. Select nutrients in the ovine uterine lumen. II. Glucose transporters in the uterus and periimplantation conceptuses. Biol Reprod. 2009:80:94-104.

69. Ehrhardt RA, Bell AW. Developmental increases in glucose transporter concentration in the sheep placenta. FASEB J. 1996;10:1132-41.

70. Molina RD, Meschia G, Battaglia FC, Hay WW. Gestational maturation of placental glucose transfer capacity in sheep. Am J Phys Regul Integr Comp Phys. 1991;261:R697-704.

71. Bergman N. Quantitative aspects of glucose metabolism in pregnant and nonpregnant sheep. Am J Phys. 1963;204:147-52.

72. Poore KR, Cleal JK, Newman JP, Boullin JP, Noakes DE, Hanson MA, et al. Nutritional challenges during development induce sex-specific changes in glucose homeostasis in the adult sheep. Am J Physiol Endocrinol Metab. 2007:292:E32-9.

73. Bell AW, Bauman DE. Adaptations of glucose metabolism during pregnancy and lactation. J Mammary Gland Biol Neoplasia. 1997;2:265-78.

74. Alexander DP, Huggett ASG, Nixon DA, Widdas WF. The placental transfer of sugars in the sheep: the influence of concentration gradient upon the rates of hexose formation as shown in umbilical perfusion of the placenta. J Physiol. 1955;129:367-83.

75. White CE, Piper EL, Noland PR. Conversion of glucose to fructose in the fetal pig. J Anim Sci. 1979;48:585-90.

76. Lunt SY. Heiden MG Vander. Aerobic glycolysis: meeting the metabolic requirements of cell proliferation. Annu Rev Cell Dev Biol. 2011:27:441-64.

77. Wen HY, Abbasi S, Kellems RE, Xia Y. mTOR: a placental growth signaling sensor. Placenta. 2005;26:S63-9.

78. Bazer FW, Burghardt RC, Johnson GA, Spencer TE, Wu G. Mechanisms for the establishment and maintenance of pregnancy: synergies from scientific collaborations. Biol Reprod. 2018;99:225-41.

79. Goodwin R. Division of the common mammals into two groups according to the concentration of fructose in the blood of the foetus. J Physiol. 1956; 132:146-56.

80. Alexander PD, Britton HG, Nixon DA. The metabolism of fructose and glucose by the sheep foetus: studies on the isolated perfused preparation with radioactively labeled sugars. Q J Exp Physiol. 1970;55: 346-62.

81. Battaglia FC, Meschia G. Principal substrates of fetal metabolism. Physiol Rev. 1978:58:499-527.

82. Wang X, Johnson GA, Burghardt RC, Wu G, Bazer FW. Uterine histotroph and conceptus development. II. Arginine and secreted phosphoprotein 1 cooperatively stimulate migration and adhesion of ovine trophectoderm 
cells via focal adhesion-MTORC2 mediated cytoskeleton reorganization. Biol Reprod. 2016;95:71.

83. Eriksson JG, Kajantie E, Osmond C, Thornburg K, Barker DJP. Boys live dangerously in the womb. Am J Hum Biol. 2010;22:330-5.

84. Kalisch-Smith Jl, Simmons DG, Dickinson H, Moritz KM. Review: sexual dimorphism in the formation, function and adaptation of the placenta. Placenta Elsevier Ltd. 2017;54:10-6.

85. Kimura K, Spate L, Green M, Murphy C, Seidel G, Roberts R. Sexual dimorphism in interferon-t production by in vivo-derived bovine embryos. Mol Reprod Dev. 2004;67:193-9.

86. Sood R, Zehnder JL, Druzin ML, Brown PO. Gene expression patterns in human placenta. Proc Natl Acad Sci U S A. 2006;103:5478-83.

87. Wang $X, W u$ G, Bazer FW. MTOR: The master regulator of conceptus development in response to uterine histotroph during pregnancy in ungulates. In: Novel insights into the role that the mechanistic target of rapamycin/mammalian target of rapamycin. Maiese K, Ed., Cambridge: Elsevier; 2016. p. 23-35.

Ready to submit your research? Choose BMC and benefit from:

- fast, convenient online submission

- thorough peer review by experienced researchers in your field

- rapid publication on acceptance

- support for research data, including large and complex data types

- gold Open Access which fosters wider collaboration and increased citations

- maximum visibility for your research: over $100 \mathrm{M}$ website views per year

At $\mathrm{BMC}$, research is always in progress.

Learn more biomedcentral.com/submissions 